Chapter 22

\title{
Carbon Nanotubes for Energy Applications
}

\author{
Dennis Antiohos, Mark Romano, Jun Chen and \\ Joselito M. Razal
}

Additional information is available at the end of the chapter

http://dx.doi.org/10.5772/51784

\section{Introduction}

\subsection{The energy problem}

The energy crisis during the 1970s sparked the development of renewable energy sources and energy conservation measures. As supply eventually met demand, these programs were scaled back. Ten years later, the hazards of pollution led to work on minimisation and reversal of the environmental impact of fossil fuel extraction, transport and consumption [1]. The United States Department of Energy predicts that 20 years from now, the world's energy consumption will increase by $20 \%$ (Figure 1). The growing concerns over the constant use of fossil fuels and its effect on climate change [2], has once again spurred research on sustainable energy development and on enhancement in renewable energy systems. Advances in energy storage and conversion systems that will make our energy usage more efficient are essential if we are to meet the challenge of global warming and the finite nature of fossil fuels $[2,3]$.

The need for the development of efficient energy storage systems is paramount in meeting the world's future energy targets, especially when energy costs are on the increase and more people need access to electricity [4,5]. Energy storage technologies can improve efficiencies in supply systems by storing the energy when it is in excess, and then release it at a time of high demand [4]. Further material progression in research and development fundamentals, as well as engineering improvements need to be continued in order to create energy storage systems that will help alleviate humanities energy storage and conversion dilemmas. 
Low grade heat (around $130^{\circ} \mathrm{C}$ ) is a by-product of almost all human activity, especially when energy conversion is involved. It is also known as "waste heat" because the dissipated heat into the environment is unutilised. Progress in the field of thermal energy conversion can lead to effective use of limited fossil fuels and provide supplemental power to current energy conversion systems [6].

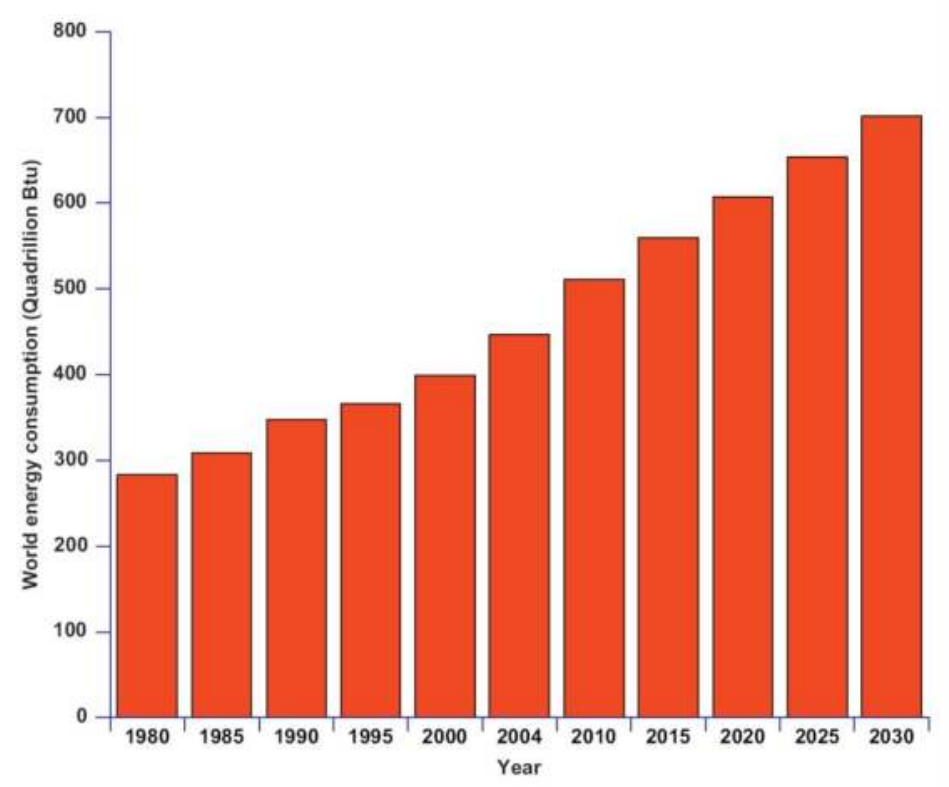

Figure 1. The United States Department of Energy values and forecasts for energy utilisation in the period from 1980 to 2030 [5]. Reproduced with permission from Elsevier.

\subsection{How and why carbon nanotubes can address the issues of energy storage and conversion}

Nanostructured materials are of great interest in the energy storage and conversion field due to their favourable mechanical, and electrical properties [3, 7]. Carbon nanotubes (CNTs) are one type of nanostructured material that possess these favourable electrical and mechanical properties due to the confinement of one dimension, combined with the surface properties that contribute to the enhanced overall behaviour. The potential of nanostructured materials is not only limited to energy storage and conversion devices; but also to nanotransistors $[8,9]$, actuators [8,9], electron field emission [8,9], and biological sensing devices $[10,11]$.

The use of carbon-based nanomaterials as electrode materials is practical and economically viable because cheap carbon pre-cursor materials are abundant [12]. As the research into 
carbon nanotubes (CNTs) has increased over the last 20 years, the cost of these materials has significantly reduced alongside improvements in processability and scalability [13].

The advantage of incorporating carbon materials and specifically CNTs as part of the electrode material is the excellent mechanical and electrical properties. They provide mechanical support to the substrate while enhancing the conductive and electrochemical properties. The low cost of the carbon precursor material used to synthesise CNTs makes device fabrication scalable and economically viable [14]. CNT assemblies can have extremely high specific surface areas, which are extremely important in capacitor design. CNT electrode materials can be confined to a smaller area increasing the electrode-electrolyte contact and decreasing the weight of the device therefore maximising the overall gravimetric performance of the device [15]. CNTs are also chemically stable, which enhances the resistance to degradation of the electrode surface [16].

\section{Supercapacitors}

\subsection{Background information}

Electrical energy can be stored in two different forms and can best be described when considering a battery and a capacitor. In a battery, it is the available chemical energy through the release of charges that performs work when two electroactive species undergo oxidation and reduction [17]; this is termed a Faradaic reaction. In a capacitor, electrostatic forces between two oppositely charged plates will separate charge. The generated potential is due to an excess and deficiency of electron charges between the two plates without charge transfer taking place [17]. The current that is observed can be considered as a displacement current due to the rearrangement of charges [2]; this effect is termed as non-Faradaic in nature.

\subsubsection{Supercapacitor operation and types}

There are two types of electrochemical capacitors that are referred to as 1) electric double layer capacitors (EDLC) and 2) pseudocapacitors. The construction of these devices can vary, with electrodes being fabricated from porous carbon materials including activated carbons, graphene, carbon nanotubes, templated carbons, metal oxides and conducting polymers $[18,19]$. EDLC or supercapacitors have two electrodes immersed in an electrolyte solution, separated by a semi-permeable dielectric that allows the movement of ions to complete the circuit but prevents a short circuit from being formed. EDLCs are advantageous as they are able to provide relatively large power densities and larger energy densities than conventional capacitors, and long life cycles compared to that of a battery and ordinary capacitor [20]. The performance of supercapacitors is affected by the power density require- 
ments, high electrochemical stability, fast charge/discharge phenomena, and low selfdischarging [21]. Table 1 below shows a comparison between the three types of devices.

\begin{tabular}{cccc}
\hline Parameters & Capacitor & Supercapacitor & Battery \\
\hline Charge time & $10^{-6}-10^{-3} \mathrm{sec}$ & $1-30 \mathrm{sec}$ & $0.3-3 \mathrm{hrs}$ \\
\hline Discharge time & $10^{-6}-10^{-3} \mathrm{sec}$ & $1-30 \mathrm{sec}$ & $1-5 \mathrm{hrs}$ \\
\hline Energy Density $(\mathrm{Wh} / \mathrm{kg})$ & $<0.1$ & $1-10$ & $20-100$ \\
\hline Power Density $(\mathrm{W} / \mathrm{kg})$ & $>10000$ & $1000-2000$ & $50-200$ \\
\hline Cycle life & $>500000$ & $>100000$ & $500-2000$ \\
\hline Charge/discharge efficiency. & $\approx 1$ & $0.90-0.95$ & $0.7-0.85$
\end{tabular}

Table 1. Comparison of key parameters for a capacitor, supercapacitor and battery [22].

Energy storage is achieved by the build-up and separation of electrical charge that is accumulated on two oppositely charged electrodes as shown in Figure 2 [12]. As stated previously, no charge transfer takes place across the electrode-electrolyte interface and the current that is measured is due to a rearrangement of charges. The electrons involved in the nonFaradaic electrical double layer charging are the conduction band electrons of the electrode. These electrons leave or enter the conduction band state depending on the energy of the least tightly bound electrons or the Fermi level of the system [2]. Supercapacitors exhibit very high energy storage efficiencies exceeding $95 \%$ and are relatively stable for up to $10^{4}-10^{5}$ cycles $[4,5]$. The energy given by the equation, $\mathrm{E}=0.5 \mathrm{CV}^{2}$, means that the operating voltage is the key in determining the energy characteristics of a supercapacitor. The choice of electrolyte when designing and fabricating a supercapacitor device dictates the operating voltage [23]. Operating voltages are approximately $1.2 \mathrm{~V}, 2.7 \mathrm{~V}$, and $3.5 \mathrm{~V}$ respectively for aqueous, organic and ionic liquid with all of them having associated advantages and disadvantages $[4,5]$. 


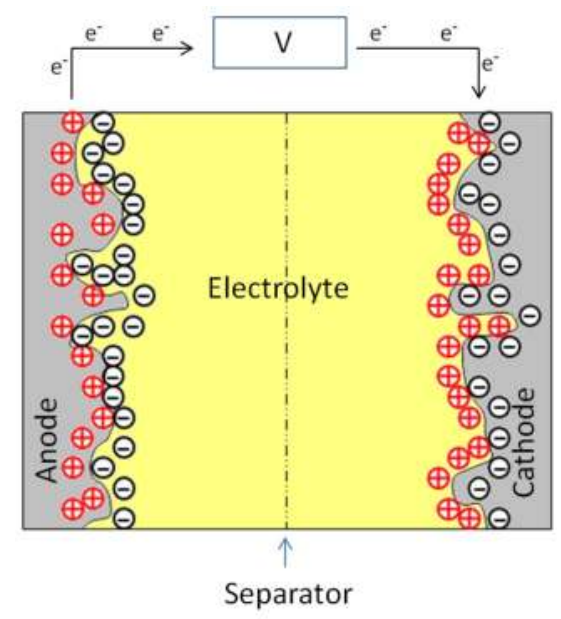

Figure 2. Schematic diagram of an EDLC supercapacitor with a positive and negative electrode, separator and porous carbon.

Like EDLC, a pseudocapacitor consists of two porous electrodes with a separator between them all immersed in an electrolyte solution [24]. However, the difference is that the charge is accumulated during Faradaic reactions near to or at the surface of the electrodes [18], hence non-Faradaic double-layer charging and Faradaic surface processes occur simultaneously [25]. The pseudocapacitance arises from a Faradaic reaction when some of the charge $(q)$ passed in an electrode process is related to the electrode potential $(V)$ via thermodynamical considerations [26]. The two principal cases are adsorption pseudocapacitance arising in underpotential deposition processes [26], and homogeneous redox pseudocapacitance where the reaction is reversible [26, 27]. Pseudocapacitors thus combine features of both capacitors and batteries [18, 28]. A comparison of energy density and power density for various electrical energy storage systems is depicted in Figure 3. Current commercial uses of supercapacitors include personal electronics, mobile telecommunications, back-up power storage, and industrial power and energy management [29, 30]. A recent application is the use of supercapacitors in emergency doors on the Airbus A380, highlighting their safe and reliable performance [30]. 


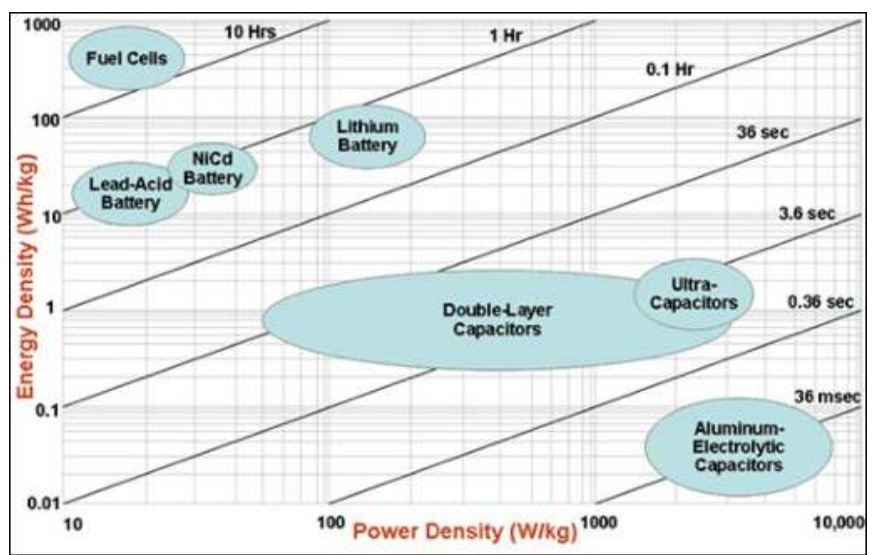

Figure 3. Ragone plot showing specific power against specific energy for various electrical energy storage systems. The times shown are the time constants of the device, which are obtained by dividing the energy density and power density [31].

\subsection{Different electrolytes used and their advantages and disadvantages}

The choice in electrolyte is extremely important for supercapacitor design as it influences the performance for energy storage and delivery. The extremely large surface area can allow for enhanced energy and power density as long as the micro-porosity and meso-porosity is tailored to suit the type of electrolyte being used. The electrolyte can be designed to enhance the cyclability, to sustain target power densities during operation, and to have an excellent rate capability (i.e. excellent charge/ discharge behaviour) [32].

\subsubsection{Aqueous electrolytes}

For aqueous electrolytes, the maximum operating voltage is theoretically limited by the reduction potential of water (1.23 V at room temperature) [32]. Most aqueous electrolyte systems tend to have an electrochemical window of approximately $1 \mathrm{~V}$ [32]. Electrolyte conductivity has a significant effect on the equivalent series resistance (esr) of the cell, which determines the power output [4]. Concentrated electrolytes are required to minimise the esr and maximise power capability [32]. In general, strong solutions of acidic electrolytes are much more corrosive than strong basic electrolytes meaning that the electrolyte has to be carefully selected for the particular electrode material.

Aqueous electrolytes tend to have very good kinetic behaviour of the electrolyte ions leading to very efficient charge/discharge rates. This behaviour is due to the relatively high conductivity and low viscosity of the concentrated solutions [4, 33]. For example, the conductivity of $1 \mathrm{M} \mathrm{H}_{2} \mathrm{SO}_{4}$ is $730 \mathrm{mS} \mathrm{cm} \mathrm{cm}^{-1}$ compared to the much lower value of $10-20 \mathrm{mS}$ $\mathrm{cm}^{-1}$ for organic solutions of lithium salts [34]. Time constants of symmetrical carbon supercapacitors using $\mathrm{H}_{2} \mathrm{SO}_{4}$ were reported to be $0.1 \mathrm{~s}$ [34]. 


\subsubsection{Organic electrolytes}

The use of non-aqueous electrolytes in supercapacitors has the main advantage of higher operating voltages compared to aqueous systems. Voltage windows can range up to $2.5 \mathrm{~V}$ and since the stored energy increases as $\mathrm{V}^{2}$, it is possible to attain large energy and power densities $[32,34]$. It must be noted that to operate at these higher voltages, non-aqueous electrolytes must be free of water and oxygen which will ensure no evolution of $\mathrm{O}_{2}$ and/or $\mathrm{H}_{2} \mathrm{O}$ at potential differences above $1.23 \mathrm{~V}$ [35]. Salts are added to the system to provide mobile ion movement at the electrode/electrolyte interface. The most common salt used generally consists of lithium ions as these ions move very well under an electric field and the effective ion diameter is very small [17].

The major disadvantages of non-aqueous systems are the lower conductivity and the higher viscosity resulting in higher equivalent series resistance (ESR) and reduced wettability if the electrode is hydrophilic. A decrease in wettability will effectively reduce the surface area used by the electrolyte, reducing the energy and power density. Most commercial systems that use organic electrolytes are manufactured in inert atmospheres and are costly to be produced [4].

\subsubsection{Ionic liquids}

Ionic liquids are another class of electrolytes that is proving a great area of research for electrolytes in supercapacitors. These electrolytes can be considered as molten salts with melting temperatures usually below room temperature where the ionic conductivity is no more than $20 \mathrm{mS} \mathrm{cm}^{-1}[34]$.

Common ions include $\mathrm{BF}_{4}{ }^{-}, \mathrm{PF}_{6}{ }^{-}\left(\mathrm{CF}_{3} \mathrm{SO}_{2}\right)_{2} \mathrm{~N}^{-}, \mathrm{CF}_{3} \mathrm{SO}_{3}{ }^{-}$as well as imidazolium, pyridinium, and quaternary ammonium salts [36]. The physical properties depend on the type of anion and cation and the alkyl chain length [37]. The main advantages are the good solvating properties, relatively high conductivity, non-volatility, low toxicity, large potential window, negligible vapour pressure and good electrochemical stability [37, 38]. Disadvantages include high viscosities and low conductivities compared to that of aqueous electrolytes; while some ionic liquid mixtures yield a potential window that is not much greater than that of aqueous systems. Capacitances approaching $100 \mathrm{~F} / \mathrm{g}$ for activated carbon (AC) electrodes have been reported by Frackowiak et. al. by using $\left(\mathrm{CF}_{3} \mathrm{SO}_{2}\right)_{2} \mathrm{~N}^{-}$anions and phosphoniumcations. Balducciet et. al. reported capacitance values of $115 \mathrm{~F} / \mathrm{g}$ for asymmetric poly(3-methylthiophene)/AC electrodes using 1-buytl-3-methyl-imidazolium ionic liquids [36, 37].

\subsection{Carbon nanotube powders}

Carbon nanotubes (CNTs) were first discovered in 1953 through research in the Soviet Union, but the first accessible results were by Sumio Iijima [39], in 1991 as a result of research into buckminster fullerenes. CNTs have a cylindrical shape that can be considered as a graphene sheet rolled up; either individually as a single-walled carbon nanotube (SWNT), or concentrically as a multi-walled carbon nanotube (MWNT) as depicted in Figure 4and Figure 5. However, these sheets can have varying degrees of twist along its length that can lead 
to the nanotubes to be either metallic or semi-conducting as the change in chiralities induces different orbital overlaps [9]. They exhibit remarkable electrical transport and mechanical properties [7], which is why interest and research into this material has increased over the last two decades. CNT powders have the potential to be tailored to specific energy storage and conversion applications with there being an added advantage that they can be used in all electrolyte environments that encompass aqueous, organic and ionic liquids [40].

\subsubsection{CNT synthesis overview}

There are a variety of different methods for making SWNTs and MWNTs that have been developed since CNTs were first discovered. These include laser ablation, arc discharge, chemical vapour deposition (CVD), and high pressure carbon monoxide disproportionation (HiPCO). Recently, work by Harris et. al. has successfully scaled-up the synthesis of CNT using a fluidised bed reactor [41]. All growing conditions for synthesising CNTs require a catalyst to achieve high yields, where the size of the catalyst nanoparticles will determine the diameter and chirality of the CNT [42]. The CNTs that are formed are generally in a mixture with other carbonaceous product including amorphous carbon and graphitic nanoparticles.

\subsubsection{Main synthesis methods for CNT growth}

Both Laser ablation and arc-discharge methods for the growth of CNTs involve the condensation of carbon atoms generated from the evaporation of carbon sources. High temperature is involved, ranging from $3000^{\circ} \mathrm{C}-4000^{\circ} \mathrm{C}$ [43]. In arc discharge, various gases such as Helium or Hydrogen are induced into plasma by large currents generated at a carbon anode and cathode. This process leads to the evaporation of carbon atoms which produces very high quality MWNTs and SWNTs [44, 45]. Laser ablation also produces very high quality CNTs with a high degree of graphitisation by focusing a $\mathrm{CO}_{2}$ laser (in pulsed or in continuous wave mode) for a period of time onto a rotating carbon target [46]. The HiPCO process utilises clusters of Fe particles as catalysts to create very high quality SWNTs [47]. Catalyst is formed in situ by thermal decomposition of iron pentacarbonyl, which is delivered intact within a cold $\mathrm{CO}$ flow and then rapidly mixed with hot $\mathrm{CO}$ in the reaction zone. Upon heating, the $\mathrm{Fe}(\mathrm{CO})_{5}$ decomposes into atoms that condense into larger clusters. SWNTs nucleate and grow on these particles in the gas phase [48, 49].

The CVD method usually consists of a furnace, catalyst material, carbon source, a carrier gas, a conditioning gas, and a collection device (usually a substrate). The carrier gas is responsible for taking the reacting material onto the substrate where $\mathrm{CNT}$ growth occurs at catalyst sites [43]. The components mentioned are essential; however, different groups and researchers have alternative experimental conditions which can contain multiple types of furnaces, and a variety of catalyst and carbon sources. The key advantage of this technique is its capability to directly deposit the CNTs onto the substrate, unlike arc discharge and laser ablation that produces a soot / powder. Recent developments by Harris et. al. [41] has led to the development of a large scale batch process for fabricating MWNTs. Here, a furnace like system called a fluidised bed reactor continuously flows a carrier gas over a porous alumina powder that is impregnated with the catalyst material, leading a to continuous creation of MWNTs where tens of grams can be synthesised in one run. 


\subsubsection{Single walled nanotubes}

SWNTs have been studied extensively as a supercapacitor and hybrid energy material $[4,50$, 51]. The structure of a SWNTis illustrated in Figure 4 with a cylindrical nature apparent as previously stated. Its advantage is that it has very good thermal and conductive properties where the thermal conductivity can exceed $6000 \mathrm{Wm}^{-1} \mathrm{~K}^{-1}$ and a potential current carrying capacity of $10^{9} \mathrm{~A} / \mathrm{cm}^{2}[52,53]$.

The maximum reported gravimetric capacitance for SWNT fabricated electrodes (PVA / PVC binder; pressed into pellet) is $180 \mathrm{~F} / \mathrm{g}$ with an energy density of $7 \mathrm{Wh} / \mathrm{kg}$ and a power density of $20 \mathrm{~kW} / \mathrm{kg}$ using $\mathrm{KOH}$ electrolyte [54,55]. Hu et. al. [56] have recently reported a solid state paper based SWNT supercapacitor, which has a specific capacitance of 115 $\mathrm{F} / \mathrm{g}$, energy density of $48 \mathrm{Wh} / \mathrm{kg}$ and a large operating voltage of $3 \mathrm{~V}$. The electrode preparation involved pre-processing where cotton sheets were immersed in the SWNT dispersion, annealed then immersed in an PVA/ $\mathrm{H}_{3} \mathrm{PO}_{4}$ electrolyte.

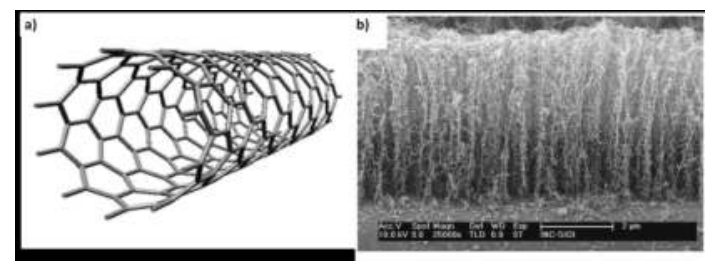

Figure 4. (a) Schematic representation of a SWNT[57].(b) FESEM of SWNTs grown onto a Si wafer substrate[58]. Reproduced with permission from Elsevier.

\subsubsection{Multi-walled nanotubes}

Like their SWNT counter parts, MWNTs have also been studied extensively as electrode materials for supercapacitors $[4,50,51]$. The advantages over SWNTs are their ability to be more easily synthesised on much larger scales, making them more suitable for commercial application. The concentric nature of MWNTs can be observed in the SEM image of Figure 5. The maximum gravimetric capacitance attained for electrodes constructed from MWNTs range between 4-140 F/g with the best available commercial result at $130 \mathrm{~F} / \mathrm{g}$ from Maxwell's Boost capacitor [59]. Wang et. al. [50] have recently reported partially exfoliated MWNTs on carbon cloth that gave a specific capacitance in the range of 130-165 F/g with a coulombic efficiency of $98 \%$. 

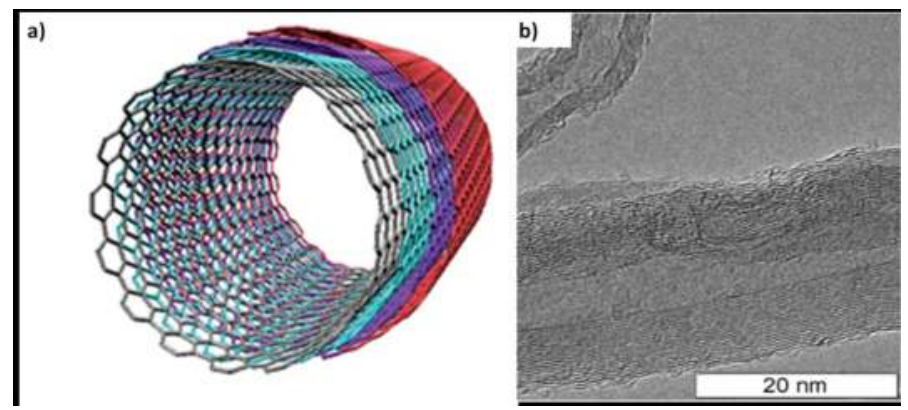

Figure 5. (a) Schematic representation of a SWNT [57]. (b) TEM images of pristine MWNTs [59]. Reproduced with permission from Elsevier

\subsubsection{Surface functionalities}

The presence of surface functionalities such as oxygen, nitrogen, hydrogen, boron and catalyst nanoparticles (dependent on the synthesis environment and pre-cursor materials) can affect the capacitative behaviour of the electrode through the introduction of Faradaic reactions [60], changes in electric and ionic conductivity [23], and influencing wettability [61]. A schematic representation of an $\mathrm{sp}^{2}$ hybridised carbon lattice with various dopants is show in Figure 6.

\section{Oxygen}

Carbon materials will have functional groups present on their surface as a result of the precursors and preparation conditions [23]. Most of these functional groups are in the form of $-\mathrm{COOH}$, $=\mathrm{CO}$ as well as phenol, quinone and lactone groups [4, 23]. Activation procedures such as post treatment with $\mathrm{H}_{2} \mathrm{SO}_{4}$ and / or $\mathrm{HNO}_{3}$ also leads to acid oxygen functionalities [4].

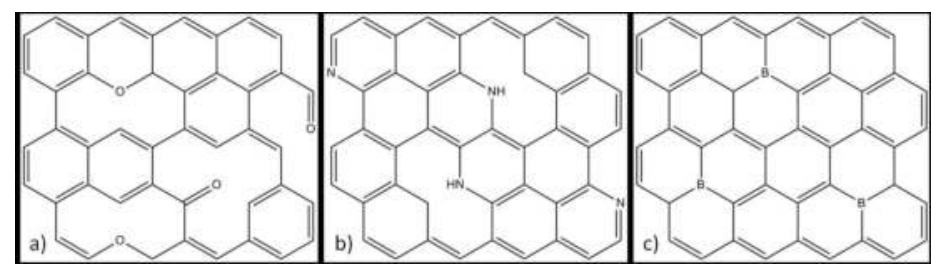

Figure 6. Schematic representation of a $\mathrm{sp}^{2}$ hybridised carbon lattice that has been doped with; (a) oxygen functional groups, (b) nitrogen functional groups, (c) boron.

Most of these groups are bonded with carbon atoms at the edge of hexagonal carbon layers where Faradaic reactions (via interactions with the electrolyte) lead to pseudocapacitance such as those developed with transition metal oxides $\mathrm{RuO}_{2}$ and $\mathrm{MnO}_{2}$ [23, 62]. These functional groups can also be purposely added onto the surface of carbons via oxidation with $\mathrm{O}_{2}$ or acid treatment with $\mathrm{HNO}_{3}$ or $\mathrm{H}_{2} \mathrm{SO}_{4}$ [63]. In aqueous systems, the presence of oxygen con- 
taining functional groups can lead to an enhanced wettability as well as pseudocapacitance as mentioned above, which maximises the electroactive surface area leading to larger energy densities $[8,23]$. It has been proposed that the pseudocapacitative reactions for oxygen functionalised CNTsinvolve carboxyl groups undergoing electron transfer[64]:

$\mathrm{C}-\mathrm{OH}--\mathrm{C}=\mathrm{O}+\mathrm{H}^{+}+\mathrm{e}^{-}$

$\mathrm{C}=\mathrm{O}+\mathrm{e}^{-}--\mathrm{C}-\mathrm{O}^{-}$

In non-aqueous systems, however, oxygen functionalities are detrimental to device performance. Parasitic redox reactions can lead to a degradation of the electrode, as well as adverse effects relating to voltage proofing and increased leakage current [4,65]. These redox reactions will reduce the cycle life of a device, as well as lowering the operating voltage.

Shenet. al. [66] reported in 2011 the effects of changing the carboxylic group concentration on SWNTs. The specific capacitance, power density and energy density $0.5 \mathrm{M} \mathrm{H}_{2} \mathrm{SO}_{4}$ electrolyte increased with carboxylic group density reaching a maximum of $149.1 \mathrm{~F} / \mathrm{g}, 304.8 \mathrm{~kW} / \mathrm{kg}$, and $20.71 \mathrm{Wh} / \mathrm{kg}$, respectively. The $10 \mu \mathrm{m}$ film electrodes were fabricated using vacuum filtration to create "bucky papers" onto a mixed cellulose estate membrane.

\section{Nitrogen}

Nitrogen containing carbons have recently attracted interest due to its n-type behaviour that promotes large pseudocapacitance, which can be obtained even if the surface area of the material is decreased [67]. In some instances, up to 3-fold increase in capacitance have been reported [68]. Typical examples of redox reactions involving nitrogen are described below [69]:

$\mathrm{C}+\mathrm{NH}+2 \mathrm{e}^{-}+2 \mathrm{H}^{+} \leftrightarrow \mathrm{CH}_{2}-\mathrm{NH}_{2}$

$\mathrm{CH}-\mathrm{NHOH}+2 \mathrm{e}^{-}+2 \mathrm{H}^{+} \leftrightarrow \mathrm{CH}_{2}-\mathrm{NH}_{2}+\mathrm{H}_{2} \mathrm{O}$

The chosen precursor material affects the types of functionalities that are attached to the carbon backbone. Nitrogen-containing groups may be added via various methods with compounds containing nitrogen including treatment with urea, melamine, aldehyde resins and polyacylonitrile [4, 70-73]. Surface areas for nitrogen-doped carbon materials are thought to be in excess of $400 \mathrm{~m}^{2} / \mathrm{g}$ [23]. This is much lower than pure SWNTs and pure MWNTs that have been reported to attain a surface area greater than $1315 \mathrm{~m}^{2} / \mathrm{g}$ and $830 \mathrm{~m}^{2} / \mathrm{g}$ respectively; suggesting that pseudocapacitance makes up a substantial portion of the total capacitance [74, 75]. Y. Zhang et. al. [76] have showed that N-doped MWNTs synthesised via CVD growth exhibited a capacitance of $44.3 \mathrm{~F} / \mathrm{g}$, which was more than twice the value obtained than that of the un-doped MWNTs in a $6 \mathrm{M} \mathrm{KOH}$ electrolyte. K. Lee et. al. [77] have shown that the nitrogen content on vertically aligned CNTs increases the capacitance until a certain point due to an increased donation of an electron by the $\mathrm{N}$ ( $\mathrm{N}$ acts as an n-type dopant) and an enhanced wettability in aqueous systems. Excessive $\mathrm{N}$-doping significantly reduced the conductivity and inhibited charge storage and delivery [77]. The doped and un-doped CNTs were directly grown onto a stainless steel substrate using CVD [77].

Boron 
Boron is another interesting material for doping CNTs due to its p-type nature which promotes $\mathrm{CNT}$ growth and increases the oxidation temperature of the nanotubes [78]. However, the development of boron doped CNTs for the use as electrodes in supercapacitor devices is not well established [23]. Work by Shiraishi et.al. showed that boron doping MWNTs, increased the capacitance per surface area from $6.5 \mu \mathrm{F} / \mathrm{cm}^{2}$ to $6.8 \mu \mathrm{F} / \mathrm{cm}^{2}$ in $0.5 \mathrm{M}$ $\mathrm{LiBF}_{4} / \mathrm{PC}$ [79]. These electrodes were once again synthesised using CVD [79]. Wang et. al. reported in 2008 that interfacial capacitance was increased by 1.5-1.6 times in boron-doped carbon than that in boron-free carbon with alkaline electrolyte $(6 \mathrm{M} \mathrm{KOH})$ and/or acid electrolyte (1 M H2SO4) [80]. The carbon material was made into a slurry using carbon black and PTFE binder and pasted onto a Ni mesh current collector [80].

\subsubsection{Advantages, limitations and comparison}

It can be seen that CNTs can be tailored different ways in order to tune (to a degree) the performance of the electrode material. This control has been demonstrated by firstly, varying the chiralitiy of the nanotube to produce the single-walled or the multi-walled variety. Both CNT types have associated advantages and disadvantages with SWNTs being able to be synthesised with a high degree of purity; while MWNTs can be synthesised on a larger scale. CNTs can also have functionalities (through addition of oxygen or nitrogen containing groups) added to their structure through treatment in order to change the surface properties and hence wettability of the material. These functionalities enable enhanced compatibility to an electrolyte to maximise electroactive surface area usage and hence performance. Further doping with specific elements such boron and nitrogen can introduce a p-type/n-type behaviour where electrons contribute a Faradaic response to the system and enhance capacitance and energy density. However, it must be noted that when faradaic processes occur at the electrode/electrolyte interface, irreversible processes increase degradation of the electrode over time. Specific capacitance of CNTs (three electrode and device testing) is in the order of $5-165 \mathrm{~F} / \mathrm{g}$ with an increase thereafter as a result of doping (i.e due to Faradaic contribution). It must be pointed out that with electrical energy devices, there is always a tradeoff between energy and power density. Therefore the electrode material has to be tailored to meet the requirements of the specific application. 


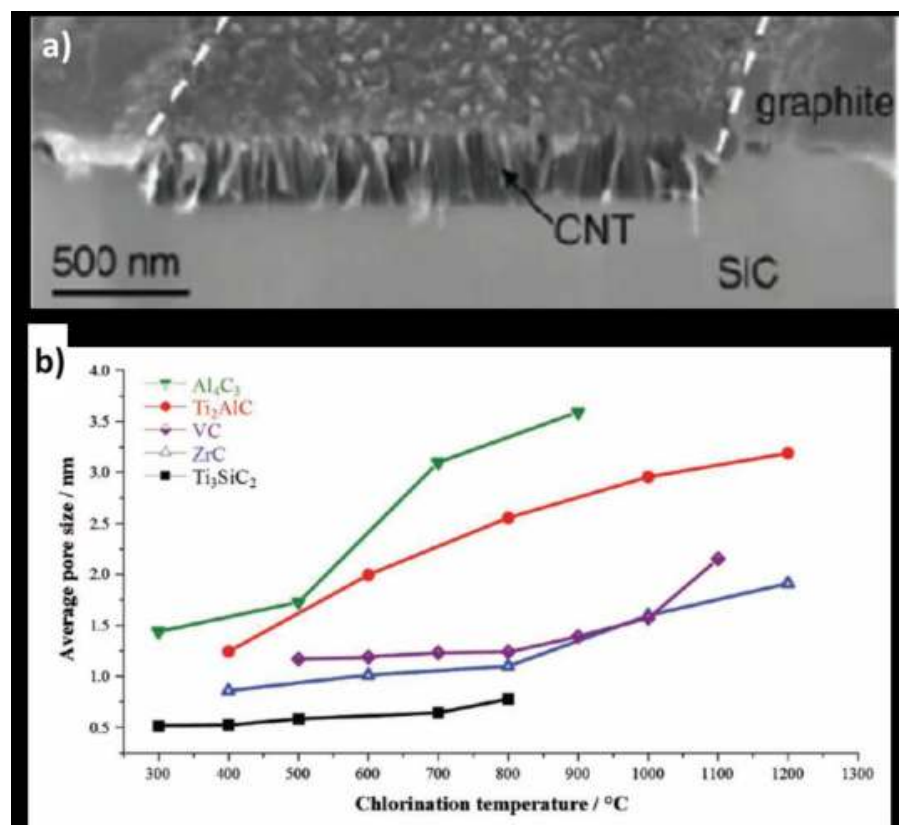

Figure 7. (a) SEM image depicting the growth of templated porous CNTs. (b) The tunability of average pore size distribution of binary and ternary carbides $\mathrm{Al}_{4} \mathrm{C}_{3}, \mathrm{Ti}_{2} \mathrm{AIC}, \mathrm{VC}, \mathrm{ZrC}, \mathrm{Ti}_{3} \mathrm{SiC}_{2}$ by varying the chlorination temperature [29]. Reproduced with permission from John Wiley \& Sons

\subsection{Templated porous carbons}

Templated porous carbons are of recent great interest in the field of energy storage due to the tunability in porosity, which is necessary to meet the materials application requirements $[29,30]$. These templated carbons are commonly known as carbide derived carbons (CDC) as the carbon materials are derived from carbon precursors through physical and/or chemical processes [29]. Briefly, the synthesis involves halogenations (usually chlorination) where the carbon is formed by selective extraction of the metal and metalloid atoms, transforming the carbide structure into pure carbon. The carbon layer is formed by inward growth, with retention of the original shape and volume of the precursor [29]. If any metal chlorides are trapped, they can be usually removed by hydrogenation or vacuum annealing [29]. The general reaction scheme is as follows where $\mathrm{M}=\mathrm{Si}, \mathrm{Ti}, \mathrm{Zr}[23,29]$;

$\mathrm{MC}(\mathrm{s})+2 \mathrm{Cl}_{2}(\mathrm{~g}) \rightarrow \mathrm{MCl}_{4}(\mathrm{~g})+\mathrm{C}(\mathrm{s})$

The advantage of forming carbon structures this way is the ability to form a tailored and narrow pore size distribution with a large surface area as can be seen in Figure 7 [29].

Inagaki et. al. in their very comprehensive review of carbon materials for electrochemical capacitors reported a maximum surface area of $S_{B E T}$ of $2000 \mathrm{~m}^{2} / \mathrm{g}$ for CDC, which gives rise to possible electrode materials with extremely large energy densities and power densities [23]. 
Gao et. al. have recently reported flexible CDC electrodes fabricated into a device which obtained a specific capacitance of $135 \mathrm{~F} / \mathrm{g}$ in $1 \mathrm{M} \mathrm{H}_{2} \mathrm{SO}_{4}$ and $120 \mathrm{~F} / \mathrm{g}$ in $1.5 \mathrm{M}$ tetraethyl ammonium tetrafluoroborate $\left(\mathrm{TEABF}_{4}\right)$ [81]. Ordered mesoporous carbon spheres with impregnated $\mathrm{NiO}$, and a maximum surface area of $944 \mathrm{~m}^{2} / \mathrm{g}$ yielded a specific capacitance of 205.3 F/g in $2 \mathrm{M} \mathrm{KOH} \mathrm{[82].} \mathrm{Reported} \mathrm{also} \mathrm{by} \mathrm{Y.} \mathrm{Korenblit} \mathrm{[83]} \mathrm{was} \mathrm{a} \mathrm{high} \mathrm{surface} \mathrm{area} \mathrm{CDC}$ $\left(2430 \mathrm{~m}^{2} / \mathrm{g}\right)$ with aligned mesopores, which yielded a specific capacitance of $170 \mathrm{~F} / \mathrm{g}$ and an extremely high capacity retention of $85 \%$ at high current densities of $20 \mathrm{~A} / \mathrm{g}$.

\subsection{Composite electrode materials}

Typical carbonaceous electrode materials (activated carbon, CNTs, graphene, CDC) with high surface areas used in supercapacitors have somewhat reached a limit when it comes energy storage capacity, thus restricting their possible applications [84]. Pseudocapacitor materials that are able to meet the needs of higher energy density are currently being developed and combined with carbonaceous materials in order to create composites that when designed into hybrid supercapacitors have advantages of fast rate capability, high storage capacity, and long cyclability[84, 85].

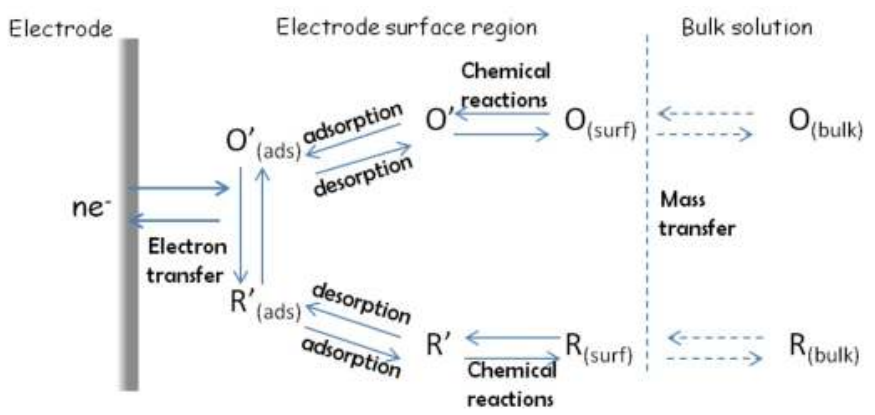

Figure 8. Schematic diagram of a reversible redox reaction, as well as EDLC occurring at the electrode/electrolyte interface leading to pseudocapacitance.

\subsubsection{CNT / polymer}

Electrode materials comprised of inherently conducting polymers (ICPs) and CNTs is a promising area of research. The conductive polymer matrix, combined with the network like structure of the CNTs provides an enhanced electronic and ionic conductivity that can considerably improve charge storage and delivery [86-88].

Antiohos et. al. reported a SWNT / Pedot-PSS composite electrode material that was fabricated into a device which had a specific capacitance of $120 \mathrm{~F} / \mathrm{g}\left(1 \mathrm{M} \mathrm{NaNO}_{3} / \mathrm{H}_{2} \mathrm{O}\right)$, coupled with an excellent stability ( $90 \%$ capacity retention) over 1000 cycles using galvanostatic charge / discharge [89]. The SWNT / Pedot-PSS composite is depicted in Figure 9 where SWNTs are thoroughly dispersed throughout the Pedot-PSS conducting polymer matrix. Kim et. al. recently fabricated a ternary composite material consisting of MWNTs, graphene, and PANI 
where a specific capacitance of $1118 \mathrm{~F} / \mathrm{g}$ was achieved. This electrode was stable with $85 \%$ capacity retention after 500 cycles using galvanostatic charge / discharge [90]. Hu et. al. [91] have recently reported a composite electrode materials containing MWNTs coated with polypyrrole that achieved a high capacitance of $587 \mathrm{~F} / \mathrm{g}$ in a $0.1 \mathrm{M} \mathrm{NaClO}_{4} /$ acetonitrile electrolyte.

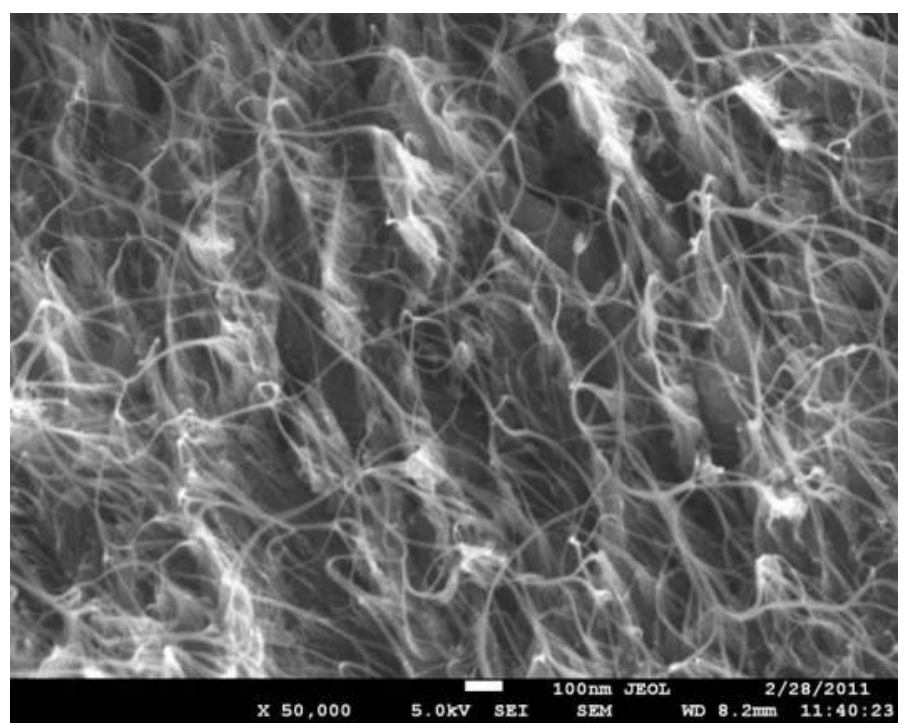

Figure 9. SEM image of PEDOT/PSS-SWNT composite showing PEDOT/PSS polymer to be integrated with the SWNT [89]. Reproduced with permission from The Royal Society of Chemistry.

\subsubsection{CNT / metal oxide}

Metal oxides exhibit pseudocapacitative behaviour over small rages of potentials, through redox processes which contribute electron transfer between the electrode / electrolyte interface (Figure 8). Common materials used in the construction of such devices are oxides of $\mathrm{Mn}, \mathrm{Ru}, \mathrm{Ir}, \mathrm{Pt}, \mathrm{Rh}, \mathrm{Pd}, \mathrm{Au}, \mathrm{Co}$ and $\mathrm{W}[22,26]$. By combining metal oxides with CNTs, composites can be formed that combine both Faradaic and non-Faradic effects enabling a larger energy density to be obtained while still holding reasonable power density. Figure 10 shows $\mathrm{MnO}_{2}$ particles that have been formed (insitu) in the presence of MWNTs.

Very recent work on carbon / metal oxide composites can be found in the review by Wang et. al. [50]. Myoungkiet. al. reported recently in their a $\mathrm{RuO}_{2} / \mathrm{MWNT}$, electrode material which achieved a specific capacitance of $628 \mathrm{~F} / \mathrm{g}$ [92]. The electrode was fabricated by dispersing the mixture in ethanol and casting onto carbon paper [92]. Li. et. al. reported that when MWNT were coated with $\mathrm{MnO}_{2}$, a capacitance of $350 \mathrm{~F} / \mathrm{g}$ was achieved [93]. More novel materials have been created by incorporating MWNTs and $\mathrm{Co}_{3} \mathrm{O}_{4}$, which yielded specific capacitances of $200 \mathrm{~F} / \mathrm{g}$ [94] (acetylene black / PVDF slurry on Ni gauze); while Jayalakshmi et. al. reported in $2007 \mathrm{~V}_{2} \mathrm{O}_{5} \cdot x \mathrm{H}_{2} \mathrm{O} / \mathrm{CNT}$ film with a specific capacitance of $910 \mathrm{~F} /$ 
gwith the material being ground into a paste with paraffin and spread onto a graphite electrode, and tested in $0.1 \mathrm{M} \mathrm{KCl} \mathrm{[95].}$

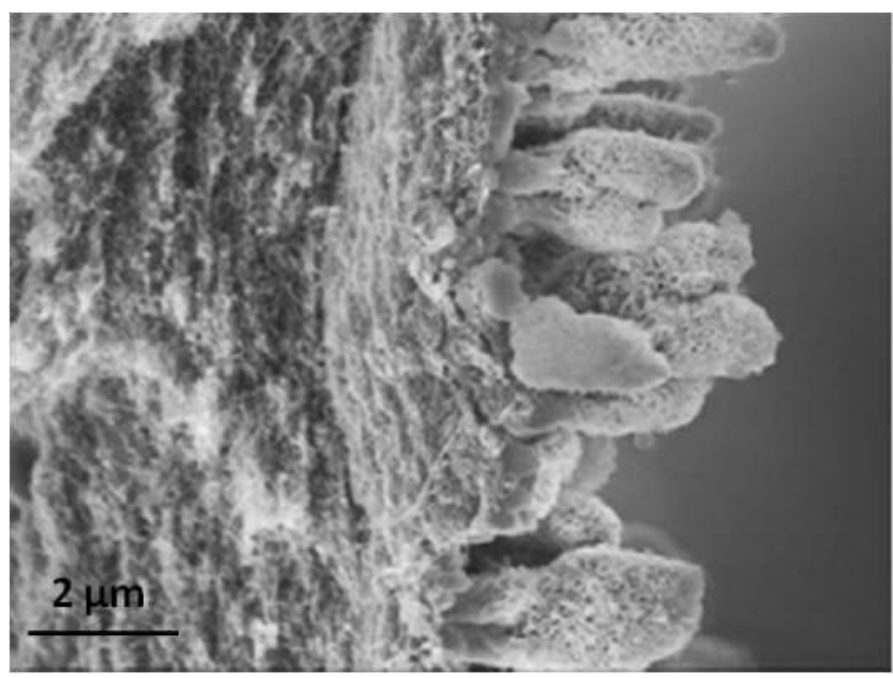

Figure 10. Surface cross-section morphology of $\mathrm{MnO}_{2}$ particles being grown (insitu) onto MWNTs[96].Reproduced with permission from Elsevier.

\subsubsection{CNT / carbons}

Creating composite materials from CNT and different forms of carbon such as graphene or carbide derived carbons (CDC) can be advantageous due to the fact that the CNTs provide microporosity (large surface area to maximise capacitance and hence energy density); while graphene and CDC can be used to tailor the mesoporosity which improve ions kinetics, enhancing the power density [21]. In Figure 11, a composite of reduced graphene oxide coated with SWNTs is depicted that has been formed into a porous film. The edges of the graphene oxide protrude out with a uniform coating of SWNTs. Recently, Li et. al. fabricated different mass loadings of graphene and CNT composite electrodes by solution casting onto glass, annealing then peeling off [97]. They reported capacitance ranges of 70-110 F/g at a scan rate of $1 \mathrm{mV} / \mathrm{s}$ in $1 \mathrm{M} \mathrm{H}_{2} \mathrm{SO}_{4}$ [97]. Luet. al. have reported a CNT / graphene composite which was bound together with polypyrrole (through a filtration process) that achieved a specific capacitance of $361 \mathrm{~F} / \mathrm{g}$ at a current density of $0.2 \mathrm{~A} / \mathrm{g}$ in $1 \mathrm{M} \mathrm{KCl}$. The electrode exhibited excellent stability with only a $4 \%$ capacity loss over 2000 cycles [97]. Dong et. al. have shown that is it possible to form SWNT/graphene oxide core shell structures and spray coat the subsequent material onto a current collector [98]. The performance of these core structures yielded a material with a specific capacitance of $194 \mathrm{~F} / \mathrm{g}$ using galvanostatic charge / discharge at a high current density of $0.8 \mathrm{~A} / \mathrm{g}$ in $1 \mathrm{M} \mathrm{KOH} \mathrm{[98].}$ 


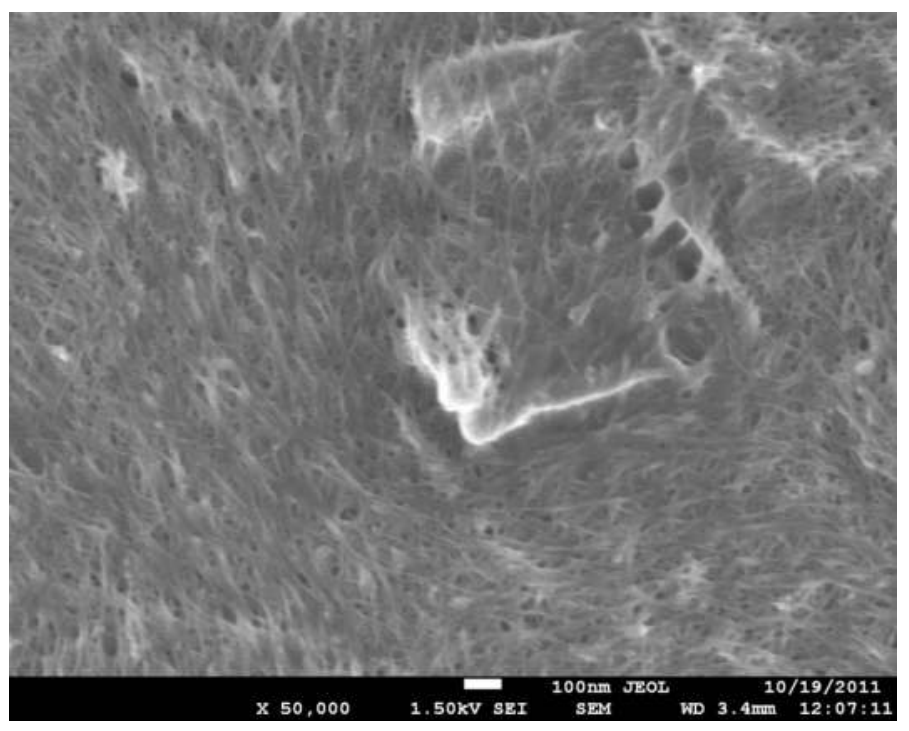

Figure 11. SEM image of a reduced graphene oxide / SWNT composite formed into a film.

\subsection{Conclusions}

It can be seen that there has been extensive research and development in the use of CNT as electrode materials for energy storage applications. Currently, they provide an excellent platform for devices that require high power density due to the very high surface areas and fast rate capability. Further studies need to be implemented in order to better understand the relationship between electrode porosity and electrolyte. An enhanced understanding of the role of micro and meso-porosity and its effect on system performance is critical. Electrolyte selection is also critical to device performance as it is proportional to the square of the voltage. The main classes of electrolytes are aqueous-based, organic-based and room temperature ionic liquids. Evolving work has focused on using CNT materials in conjunction with doping of various functional groups such as carboxyls, amines and elements such as boron and nitrogen in order to enhance the electrode performance through increased usage of electrode surface area and / or Faradaic contributions. The most recent work has focused on the creation of composite materials via the combination of CNTs with conducting polymers or metal oxides. CNT composites have amassed into a prevalent area of research through the search for the discovery of hybrid energy storage devices that are able to have high energy and high power density which are beneficial for creating more energy efficient systems and providing a greater range of applications. 


\section{Thermal Energy Harvesting}

\subsection{Introduction to thermogalvanic cells}

Studies on the conversion of heat to electricity have been conducted as early as the 1960s [99]. Since then, several thermal converters have been developed: thermocouples, thermionic converters, thermally recharged cells, thermogalvanic cells, etc. [100]. The discussion in the subsequent sections will be limited to thermogalvanic cells, also known as thermocells. These are electrochemical systems that are able to directly transduce thermal energy to electrical energy [101]. The simple design of these systems allows them to function without the need for moving components. Their stability allows operation for extended periods without regular maintenance. Thermocells also have zero carbon emission hence it will not contribute to the environmental impact of electrical power generation.

\subsubsection{Low grade heat sources and conversion through thermogalvanic cells}

\section{Various unharnessed low grade heat sources}

The second law of thermodynamics dictates that a heat engine can never have perfect efficiency and will always produce surplus heat (usually around $100{ }^{\circ} \mathrm{C}$ ). This waste heat (or low grade heat) is one of the world's most ubiquitous sources of untapped energy. (i.e. waste heat is produced by simply turning on an automobile). Roughly $70 \%$ of the energy generated by an automobile motor is wasted; part of it ends up as a hot exhaust pipe and warm brakes. The Wartsila-Sulzer RTA96-C turbocharged two-stroke diesel engine, one of the most efficient engines in the world, is only able to convert around $50 \%$ of the energy in the fuel to useful motion. The rest of that energy gets dissipated as waste heat [102]. Waste heat also exists in factories, particularly in the steel and glass production industry. Pipes that carry hot liquids are also low grade heat sources. Other scenarios wherein heat simply dissipates into the environment are power plants, household appliances, and various electronic gadgets. Research done to convert waste heat into electrical power by the use of ferromagnetic materials, thermocouples and thermionic converters has resulted in low efficiencies [103-105]. Advances in thermoelectric systems have been hampered by its high initial cost and material limitations; as these systems operate in the temperature range much higher than low grade heat [106].

\section{Description of how a thermogalvanic cell works}

A thermogalvanic cell, also known as a thermocell, is a thermal energy converter that utilises electrochemical reactions to attain conversion of low grade heat to electrical power. The two half cells of the system are held at different temperatures causing a difference in redox potentials of the mediator at the anode and cathode [107]. This reaction can drive electrons through an external circuit that allows generation of current and power. A schematic of a thermocell with a ferri/ferrocyanide redox couple is shown in Figure 12. 


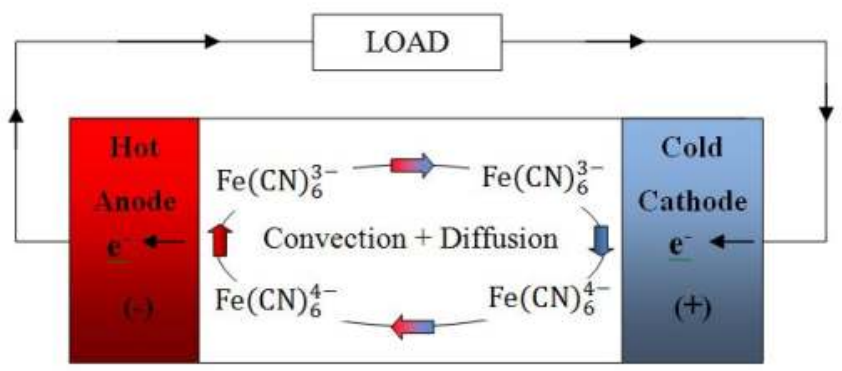

Figure 12. Ferri/Ferro Cyanide redox thermogalvanic cell [108]Reproduced with permission from Springer Science + Business Media

Ferrocyanide is oxidized at the hot anode, the electron generated then travels through an external circuit and returns to the cell via the cold cathode where it is consumed in the reduction of ferricyanide[109]. The accumulation of reaction products at either half-cell is prevented by the diffusion and convection of the electrolyte that occurs naturally, thus eliminating the need for moving mechanical components.

\subsubsection{Desirable material properties for thermal conversion cells}

Power conversion efficiency and how it is affected by electrode material properties

The power conversion efficieny $(\Phi)$ of a thermocell is defined as follows:

$$
\Phi=\frac{\text { Electrical output power }}{\text { Thermal power flowing through the cell }}
$$

The thermal power flowing through the cell is largely controlled by cell design and electrolyte selection. When a reversible redox couple is used, no net consumption of the electrolyte occurs and the thermal power is given by:

$$
\text { Thermal power flowing through cell }=K A \frac{\Delta T}{d}
$$

Where $\mathrm{K}$ is the thermal conductivity of the electrolyte, $\mathrm{A}$ is the electrode cross sectional area, $\Delta \mathrm{T}$ is the thermal gradient and $\mathrm{d}$ is the distance between the two electrodes [110].

Qualitative behaviour of the current and voltage dependencies are shown in Figure 13; it depicts that the maximum electrical output power $\left(\mathrm{P}_{\max }\right)$ is obtained when the external and internal loads are equal and is given by:

$$
\mathbf{P}_{\text {max }}=0.25 \mathbf{V}_{\text {OC }} \mathbf{I}_{\text {SC }}
$$


Where $\mathrm{V}_{\mathrm{oc}}$ is the open circuit voltage and $\mathrm{I}_{\mathrm{sc}}$ is the short circuit current. $\mathrm{V}_{\mathrm{oc}}$ is highly dependent on the reaction entropy of the redox couple and the thermal gradient at which the electrodes are exposed to as shown in Equation 4:

$$
\mathrm{V}_{\mathrm{oc}}=\frac{\Delta \mathrm{S}_{\mathrm{B}, \mathrm{A}} \Delta \mathrm{T}}{\mathrm{nF}}
$$

where $\Delta S_{B, A}$ is the reaction entropy for a hypothetical redox couple $A \leftrightarrow n e^{-} B, n$ is the number of reactions involved in the redox reaction and $\mathrm{F}$ is Faradays constant [100].

Combining Equation 2 and Equation 3 allows the power conversion efficiency to be expressed as:

$$
\boldsymbol{\Phi}=\frac{0.25 \mathbf{V}_{o c} \mathbf{I}_{\mathrm{sc}}}{\mathrm{KA}\left[{ }^{\Delta \mathrm{T}} / \mathrm{d}\right]}
$$

Ohmic, mass transport and activation overpotentials are losses that need to be minimised in order to realise an improvement in thermocell conversion efficiency. At large electrode separations, ohmic overpotential is dictated by the electrolyte resistance; and mass transport overpotential is maximized. By decreasing the inter-electrode separation, an increase in generated power will be observed as both ohmic and mass transport overpotentials will decrease. However, the power conversion efficiency will be lowered as it will be harder to maintain the thermal gradient in the cell [112]. It has been shown that changes in electrolyte concentration affect its thermal conductivity [108]. Optimization of electrolyte concentration coupled with appropriate cell design is necessary to mitigate both overpotentials while maintaining large power conversion efficiency.

Activation overpotential is associated with the activation barrier needed to transfer an electrode to an analyte. For the same activation overpotential, larger current densities are realised when the exchange current density is increased. This increase is attained when the concentration of the redox couple in the electrolyte is maximised, the thermal gradient is increased and the number of possible reaction sites is augmented [113]. Porous electrodes have the advantage of increased electroactive surface area and will directly amplify the short circuit current density [114]. It must be noted that for porous electrodes, short circuit current density does not increase indefinitely with electrode thickness as mass transfer overpotential will become limiting. The reaction products formed within the pores of the anode will not be able to diffuse fast enough to the cathode and vice versa, generating concentration gradients around both electrodes. Another way to decrease the activation overpotential in thermocells is by using catalytic electrodes attained by doping [115]. 

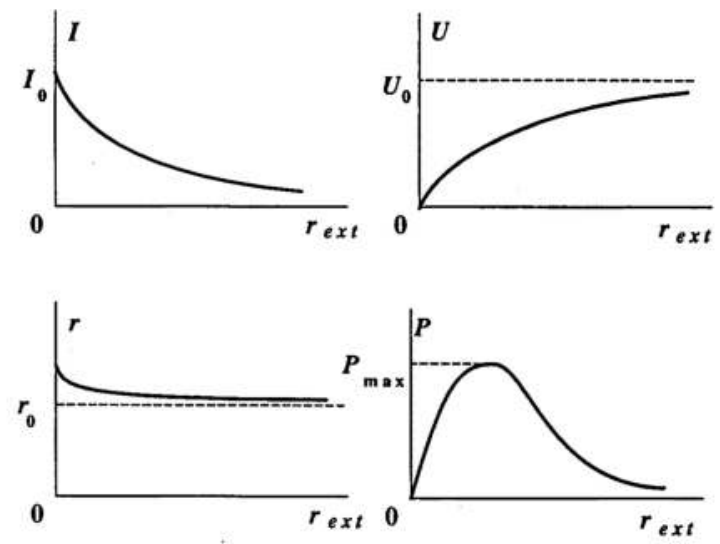

Fig. 2. The typical dependences of the current $I$, the effective voltage $U$, the internal resistance $r$ and the useful power from the external resistance $r_{\text {ext }}$.

Figure 13. The typical dependencies of the current $(I)$ on the effective voltage $(U)$, internal resistance $(r)$ and the useful power on the external resistance $\left(r_{\text {ext }}\right)$ [111]Reprinted with permission from Elsevier.

\subsubsection{CNTs vs flat electrodes - why CNTs can improve thermal harvesting}

Power conversion efficiency achieved by using flat electrodes and why recent developments in CNTs can augment thermogalvanic cell performance

The chemical stability of platinum led to its extensive investigation in thermogalvanic cells. In fact, a study on the effects of platinum electrode cleaning was performed and it was deduced that this affects the power delivery characteristics of thermogalvanic cells [116].

Comparison of thermoelectric converters operating at different conditions (i.e. thermal gradient, electrolyte, electrode separation, etc.) can be done by measuring their power conversion efficiency relative to a Carnot engine operating at the same temperature $\left(\Phi_{\mathrm{r}}\right)$.

$$
\Phi_{\mathrm{r}}=\frac{\Phi_{\text {thermogalvanic cell operating at } \Delta \mathrm{T}}}{\Phi_{\text {Carnot engine operating at } \Delta \mathrm{T}}}
$$

If power inputs are ignored, such as mechanical stirring, thermocells with platinum electrodes are able to attain power conversion efficiency relative to a Carnot engine of $1.2 \%$. However, if power inputs are strictly excluded, the efficiency drops to $0.5 \%$ [100].

As mentioned previously, the discovery of CNTs led to widespread research on this material to investigate its potential uses, one of them being electrochemical applications [39, 117-120]. CNT electrodes are known to exhibit Nernstian behaviour and more importantly, fast electron transfer kinetics with the redox couple ferri/ferrocyanide. Peak potential separation in cyclic voltammograms obtained using micron-sized MWNT electrodes and $5 \mathrm{mM}$ potassium ferrocyanide is $59 \mathrm{mV}$, which is the expected theoretical value and implies that 
the highest electron transfer rate was attained [121]. Incidentally, the ferri/ferrocyanide redox couple has been studied intensively in thermocell applications owing to the large voltage that can be induced by a thermal gradient, also known as the Seebeck coefficient. The Seebeck coefficient $1.4 \mathrm{mV} / \mathrm{K}$ for the ferri/ferro cyanide redox couple implies that an open circuit potential of $84 \mathrm{mV}$ is attainable at a thermal gradient of $60{ }^{\circ} \mathrm{C}$ (the usual limit for aqueous systems without significant cooling). The fast electron transfer of CNTs in ferri/ ferro cyanide primarily justifies its use as electrodes in thermocells.

The nanometre diameter of CNTs gives rise to large gravimetric and volumetric specific surface areas (SSA). Their unique aspect ratios allow porous electrodes to be fabricated by a variety of methods. Theoretically the SSA of CNTs can range from $50-1315 \mathrm{~m}^{2} / \mathrm{g}$, the value dictated by the number of walls [74]. Theoretical predictions are in good agreement with experimental values obtained by the measurement of amount of gas (usually $\mathrm{N}_{2}$ ) adsorbed at $77 \mathrm{~K}$ and calculations using the Brunauer-Emmett-Teller (BET) isotherm. Kaneko et al. [122] have reported that MWNTs are mesoporous while Rao et al. [123] have shown that SWNTs are microporous. MWNT buckypapers of the same geometric area compared with platinum foil are known to have three times larger charging current density during cyclic voltammetry in ferri/ferrocyanide aqueous electrolyte [114], evidence of the large accessible SSA of CNT electrodes.The large SSA of CNTs allows for a greater number of electroactive sites. When the CNT electrode porosity is controlled and the tortuousity is minimised in thermogalvanic cells (so that mass transfer is not limited within the electrode), the short circuit current generated can be significantly augmented.

\subsection{Different types of CNTs investigated}

\subsubsection{SWNT and MWNT}

CNTs were first used as thermocell electrodes in 2009 [114]. Baughman et al. tested $0.5 \mathrm{~cm}^{2}$ MWNT buckypaper electrodes (with less than $1 \%$ catalyst and with MWNT diameter of around $10 \mathrm{~nm}$ ) in a U-Cell with electrode separation of $5 \mathrm{~cm}$, a temperature gradient of $60^{\circ} \mathrm{C}$ wherein $\mathrm{T}_{\text {cold }}=5^{\circ} \mathrm{C}$. A schematic of the cell they used is shown in Figure 14. A specific power density of $1.36 \mathrm{~W} / \mathrm{m}^{2}$ was obtained [114]. Platinum electrodes tested under the same conditions generated a specific power density of $1.02 \mathrm{~W} / \mathrm{m}^{2}$, proving that CNTs are viable materials for thermocell electrodes.

SWNT powders produced by arc discharge (ASA-100F, Hanwha Nanotech) with an average diameter of $1.3 \mathrm{~nm}$, and composition of 20-30 wt. \% CNTs, $40 \mathrm{wt}$. \% carbon nanoparticles, 20 wt. \% catalyst material, $10 \mathrm{wt} \%$ amorphous carbon and graphite, was tested by Kang et al. in thermal harvesting [113]. A vertical test cell with a "hot above cold" orientation (Figure 15), glass frit separator and electrode separation of $4 \mathrm{~cm}$ was employed with $\mathrm{T}_{\text {hot }}=46.4{ }^{\circ} \mathrm{C}$ and $\mathrm{T}_{\text {cold }}=26.4{ }^{\circ} \mathrm{C}$. SWNT electrodes with an area of $0.25 \mathrm{~cm}^{2}$ were immersed in $0.2 \mathrm{M}$ $\mathrm{K}_{3} \mathrm{Fe}(\mathrm{CN})_{6} / \mathrm{K}_{4} \mathrm{Fe}(\mathrm{CN})_{6}$ electrolyte. The specific power density obtained was around 5.15 $\mathrm{W} / \mathrm{kg}$. Commercially available purified SWNT powders (P-SWNT) sourced from Hanwha Nanotech (ASP-100F), refined by thermal and acid treatment (60-70 wt. \% nanotubes, $10 \mathrm{wt}$. $\%$ catalyst material, 20 wt. \% graphite impurities) was tested by the same group. The specific 
power density improved by $32 \%$, generating $6.8 \mathrm{~W} / \mathrm{kg}$. Using the same test conditions, commercially available purified MWNT having 3-6 walls with a median diameter of $6.6 \mathrm{~nm}$ (SMW100, Southwest Nanotechnologies, Inc) and approximately 98 wt. \% carbon yielded a specific power density of $6.13 \mathrm{~W} / \mathrm{kg}$. It must be noted that these tests were not done to maximise the power generation capability of the thermocell but to gain further insight into CNT electrodes for thermal harvesting. Hence the small electrode separation, low electrolyte concentration and small thermal gradient.

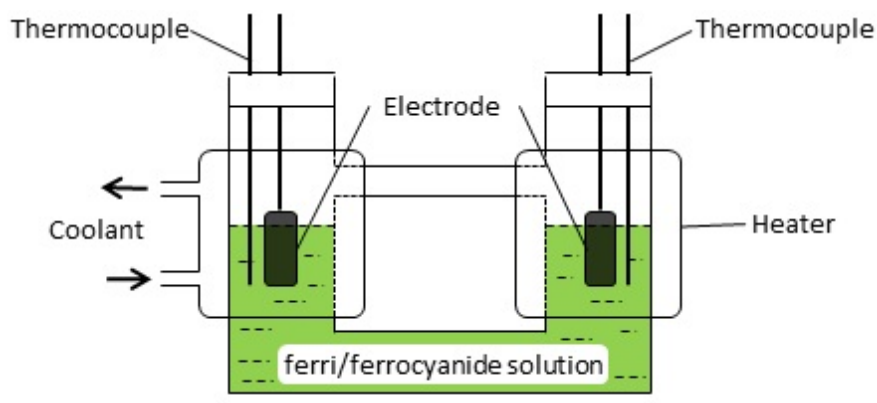

Figure 14. Schematic of the U-Cell used by Baughman et. al for thermal harvesting

Electrical impedance spectroscopy (EIS) of the various carbon nanomaterials tested by Kang et al revealed that the P-SWNT electrode has a marginally lesser ohmicoverpotential $(21 \Omega)$ than the pristine SWNT $(22 \Omega)$. This finding explains the increased specific power density generated when the P-SWNT electrodes are used.
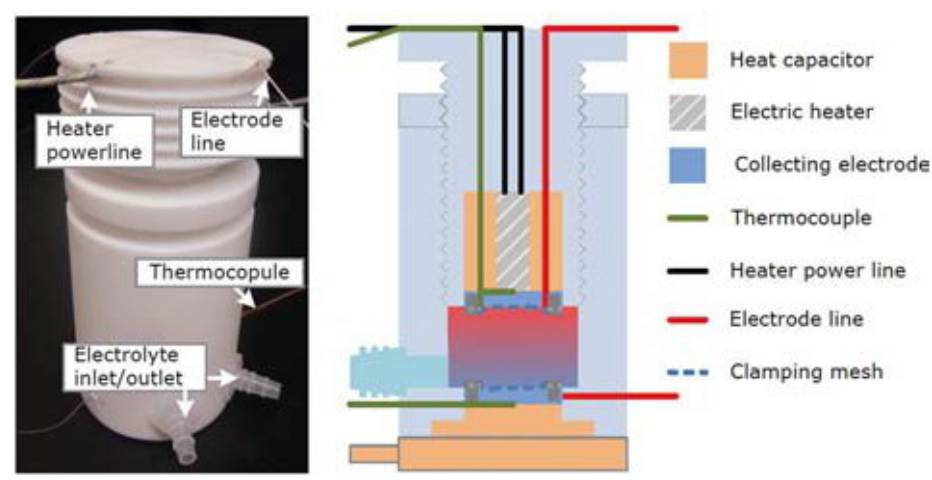

Figure 15. Vertical "hot above cold" thermocell[113]Reprinted with permission from John Wiley \& Sons, Inc.

It has been proven that the catalytic nature of MWNTs is due to the edges or sites where the tube terminates, regions that are more numerous in MWNTs than in SWNTs [124]. Due to this and the fact that P-MWNTs had lower ohmic resistance (18 $\Omega$ ) compared to P-SWNTs, it 
was expected that P-MWNTs would perform better in thermal harvesting. The authors attributed the enhanced performance of P-SWNT to the larger specific surface area, which compensated for the decreased electroactive sites and higher ohmic resistance.

\subsubsection{Functionalized CNTs}

Functionalising or doping (using Nitrogen or Boron atoms) may be used to fine tune the physical and chemical properties of CNTs [125-127]. With advances in technology, CNT functionalization is a reasonably simple process [128]. Dai et. al have shown that nitrogendoped carbon nanotubes (NCNTs) have high electrocatalytic activity in oxygen reduction reactions as compared to undoped CNTs [129]. The increase in performance was brought about by a four electron pathway for oxygen reduction reactions that was attained by aligning the nanotubes and integrating nitrogen into the carbon lattice. The additional electrons contributed by nitrogen atoms can enhance electronic conductivity by providing electron carriers for the conduction band [130]. The many active defects and hydrophilic properties of NCNTs allow for enhanced electrolyte interaction in aqueous solutions [131]. Boron doped CNTs (BCNTs) are also attractive for electrochemical applications owing to the increased edge plane sites on the CNT surface; proven to be the predominant region for electron transfer [132]. Examples of the electrocatalytic performance of BCNTs are the improved detection of Lcysteine, enhanced electroanalysis of NADH and enhancement of field emission [126, 127,133].

The possibility of using nitrogen-doped CNT and boron-doped CNT electrodes in thermocells was investigated by Cola et.al [115]. Doping was attained by using a plasma-enhanced chemical vapour deposition process. Tests were run using a U-cell configuration (Figure 14), $\mathrm{T}_{\text {cold }}=20^{\circ} \mathrm{C}$, thermal gradient of up to $40^{\circ} \mathrm{C}$, and electrolyte concentration of $0.1 \mathrm{M}$ potassium ferri/ferrocyanide. The electrodes were sized to $0.178 \mathrm{~cm}^{2}$ and were set up in a symmetric and asymmetric (N(hot)-B(cold) and $\mathrm{B}($ hot $)-\mathrm{N}($ cold)) fashion.

Results (Figure 16a) indicate inferior thermocell performance for both NCNT and BCNT as compared to Pt and pristine CNTs. The poor performance of the doped CNTs was brought about by the sluggish kinetics, evidenced by the large peak separations in the cyclic voltammograms taken at a scan rate of $100 \mathrm{mV} / \mathrm{s}$ (Figure 16b). It was theorized that the slow-moving kinetics for the doped electrodes was caused by the electrostatic effects at the electrodeelectrolyte interface [134]. The positively charged BCNTs repulsed the similarly charged potassium $\left(\mathrm{K}^{+}\right)$counter ion which decreased the electrolyte concentration in the vicinity of the electrode. The negatively charged NCNTs led to a strong electrostatic attraction with $\mathrm{K}^{+}$, an effect which at low concentrations can improve electron transfer kinetics. However, the large bulk concentration (needed to achieve significant short circuit currents in thermocells) led to a high density of the $\mathrm{K}^{+}$ions in the vicinity of the electrode. This effectively acted as a barrier to the redox reactions that were supposed to occur at the electrode. 

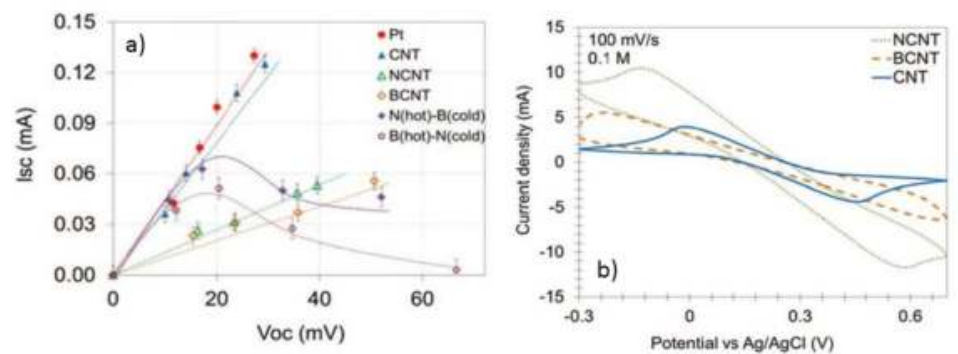

Figure 16. a) Thermal energy conversion response of various electrodes used by Cola et. Al b.Cyclicvoltammograms of various electrodes in $0.1 \mathrm{M} \mathrm{K}_{3} \mathrm{Fe}(\mathrm{CN})_{6} / \mathrm{K}_{4} \mathrm{Fe}(\mathrm{CN})_{6}$ at $100 \mathrm{mV} / \mathrm{s}$ vs $\mathrm{Ag} / \mathrm{AgCl}$ reference electrode [115]. Reproduced with permission from J. Electrochem. Soc.

Using BCNT and NCNT in an asymmetric configurations resulted in increased currents at small thermal gradients as compared to the symmetric arrangements. This current then decreased non-linearly as the temperature difference was increased. At small thermal gradients, with the BCNT at the cold side of the cell, the slower kinetics induced an accumulation of reactants at its surface. The faster kinetics at the NCNT, brought about by the increased temperature, kept the electrolyte concentration in its vicinity low. Both factors allow the redox reactions to occur rapidly until a threshold thermal gradient is reached. At this point, the ion concentration in the vicinity of the NCNT is sufficiently large to slow the kinetics and reduce the currents generated. The threshold temperature gradient is attained at lower temperatures when the NCNT is kept at the cold side of the cell because the slower kinetics at this temperature promotes accumulation of $\mathrm{K}^{+}$ions on the NCNT surface and leads to the "blocking" effect discussed previously.

\subsubsection{Composites}

The recent discovery of graphene through micromechanical exfoliation has sparked a flurry of research into its possible applications [135]. Graphene consists of a single layer of carbon atoms bonded in a hexagonal lattice. Like CNTs, its remarkable properties (charge carrier mobility of $200000 \mathrm{~cm}^{2} / \mathrm{V}$-s and specific surface area of $2630 \mathrm{~m}^{2} / \mathrm{g}$ ) make it an ideal candidate for electrochemical applications [136, 137]. In order to scale up graphene production, graphite is normally exfoliated in the liquid state through surfactant/solvent stablilization [138] or chemical conversion resulting in a graphene like structure known as reduced graphene oxide (RGO), shown in Figure 17 [139]. Being of the same composition as CNTs, investigation of the possibility of synthesizing composites of these two carbon materials and exploring their performance as electrode materials has been done by several research groups [83, 91, 140]. 


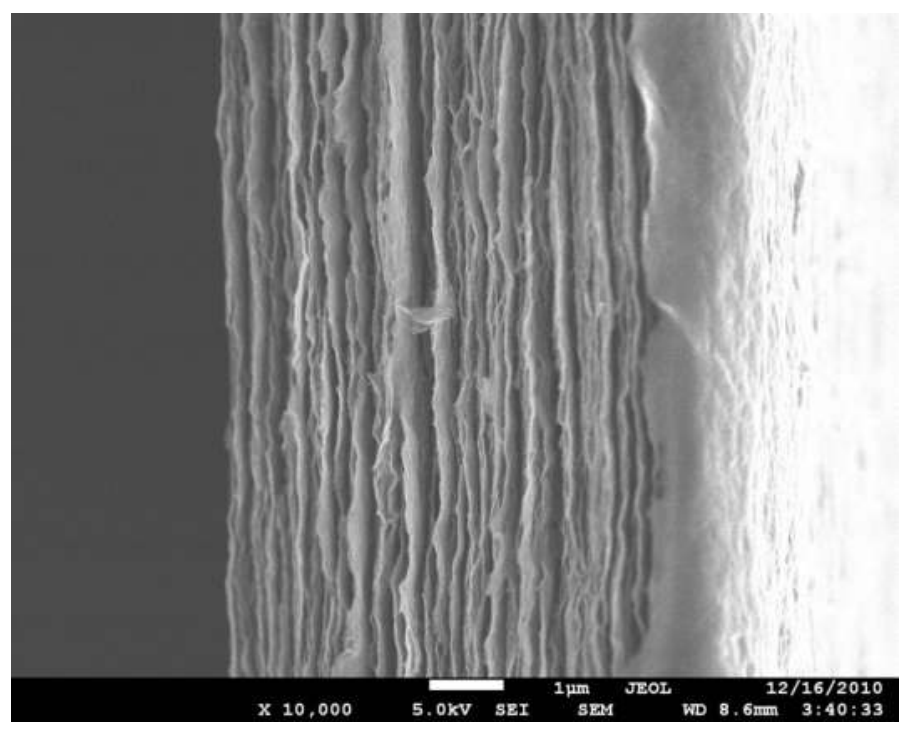

Figure 17. SEM image of the cross section of a reduced graphene oxide film

Kang et al. have shown that when composites composed of 1:1 weight RGO and P-SWNT are used in thermocells, the specific power generated $(5.3 \mathrm{~W} / \mathrm{kg})$ is comparable to that of SWNTs (the experimental conditions used were discussed in section 3.2.1) [113]. It must be noted that when RGO alone is used, the specific power generated is $3.87 \mathrm{~W} / \mathrm{kg}$. However, the composite electrode produces a specific power that is only $78 \%$ of the P-SWNT. This decrease in performance can be attributed to the large ohmic resistance observed in the RGO electrode $(35.6 \Omega)$ that is $55 \%$ higher than the P-SWNT electrode. The chemical conversion of graphite to RGO involves oxidising graphite, exfoliation and then a subsequent reduction. It is surmised that the incomplete removal of the oxygen containing functional groups is the cause of the pronounced ohmic resistance. Another reason for the poor performance of the composite electrodes is the restacking of the RGO sheets during electrode preparation, which impedes electrolyte diffusion and results in sluggish kinetics.

Optimisation of the RGO-SWNT composition for thermocell electrodes was done by Chen et. al [141]. The amount of RGO added ranged from 1 to $20 \%$ by weight. A U-cell was used with $0.75 \mathrm{~cm}^{2}$ electrodes separated by $10 \mathrm{~cm}$, a thermal gradient of $60{ }^{\circ} \mathrm{C}$ with $\mathrm{T}_{\text {cold }}=20^{\circ} \mathrm{C}$ and $0.4 \mathrm{M}$ ferri/ferrocyanide electrolyte. The optimised composite $99 \%$ SWNT-1 \% RGO generated a specific current density of $26.78 \mathrm{~W} / \mathrm{kg}$. By using large amounts of SWNTs the RGO sheets were prevented from restacking, which resulted in the appropriate nanoporosity that promoted redox mediator diffusion. The sheet like structure of the RGO provided increased pathways for electrons in the composite thus contributing to its enhanced performance. The interaction between SWNTs and RGO is clearly seen in Figure 18. 


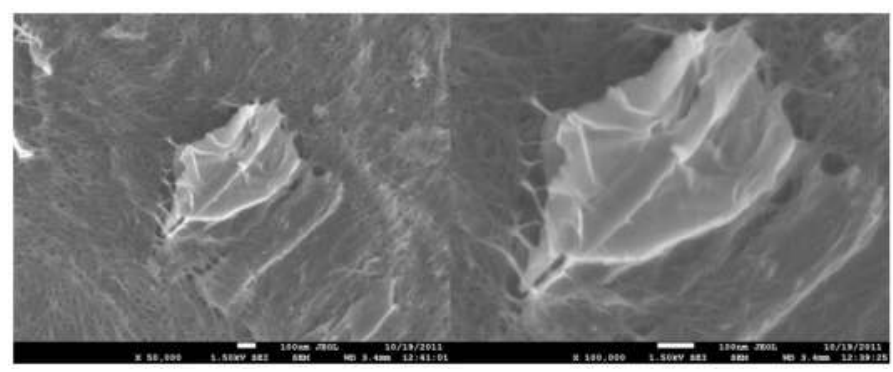

Figure 18. SEM images of reduced graphene oxide-SWNT composites

\subsection{Developments in processing and fabrication of CNTs for better cell design}

\subsubsection{Current processing techniques for CNTs relevant to thermocells}

\section{Solvent/surfactant exfoliation}

One of the major obstacles to research on CNT characterisation and application is their spontaneous aggregation brought about by attractive van der Waals interactions in both aqueous and organic solutions. The resulting aggregates or "bundles" can reach lengths of several microns and diameters of tens of nanometers. Debundling of these aggregates is essential as they have mediocre properties as compared to individual tubes. Reproducibility of results also becomes an issue when CNTs are not dispersed adequately.

Liquid phase separation is one of the simplest methods wherein stable CNT dispersions are attainable. Stable well-exfoliated CNT dispersions is achieved by appropriate selection of the solvent as forced dispersion via ultrasonication will result in agglomeration of the CNTs in a very short span of time. Selection of solvents can be based on the enthalpy of mixing per solvent volume $\left(\Delta H_{\text {mix }}\right)[138]$ :

$$
\Delta \bar{H}_{m i x}=\frac{2}{R_{b u n}}\left(\delta_{N T}-\delta_{s o l}\right)^{2} \varnothing
$$

Where $R_{b u n}$ is the radius of the dispersed nanotube bundles, $\delta_{N T}$ and $\delta_{\text {sol }}$ are square roots of the nanotube and solvent surface energies and $\varnothing$ is the nanotube volume fraction. The solubility theory states that a negative free energy of mixing ( $\left.\Delta G_{m i x}\right)$ is indicative of a stable dispersion.

$$
\Delta \bar{G}_{m i x}=\Delta H_{m i x}-T \Delta \bar{S}_{m i x}
$$


The entropy of mixing per unit volume ( $\Delta S_{\text {mix }}$ ) of nanotubes is generally small owing to their size and rigidity [142]. In order to realize a minimisation of $\Delta G_{m i x}$ then solvents which result in small values of $\Delta H_{\text {mix }}$ are necessary. Based on Equation 7, the most effective solvents at dispersing CNTs would be those that have a surface energy close to the nanotube surface energy $\left(\sim 70 \mathrm{~mJ} / \mathrm{m}^{2}\right)$; i.e. solvents with surface tension around $40 \mathrm{~mJ} / \mathrm{m}^{2}$ [143].

Another method to attain stable dispersions of CNTs is through the use of surfactants. Its inherent advantage over solvent dispersion was the fact that it was carried out in aqueous media, lessening its hazards and environmental impact. It relies on the principle wherein colloids are stabilized by surface charges [144]; i.e. Coulomb repulsion. Adsorption of the amphiphilic surfactant molecules onto CNTs is attained through their hydrophobic tails. This introduces a removable surface charge that creates an electric double layer around the nanotube; of which the magnitude and sign is proportional to its zeta potential [145]. This double layer provides repulsive forces that counteract the attractive van der Waals forces [146]. Selection of surfactants for CNTs dispersion depends on the size of their molecules. Low molecular weight surfactants will be able to pack tightly around the nanotube surface resulting in better stabilization [147].

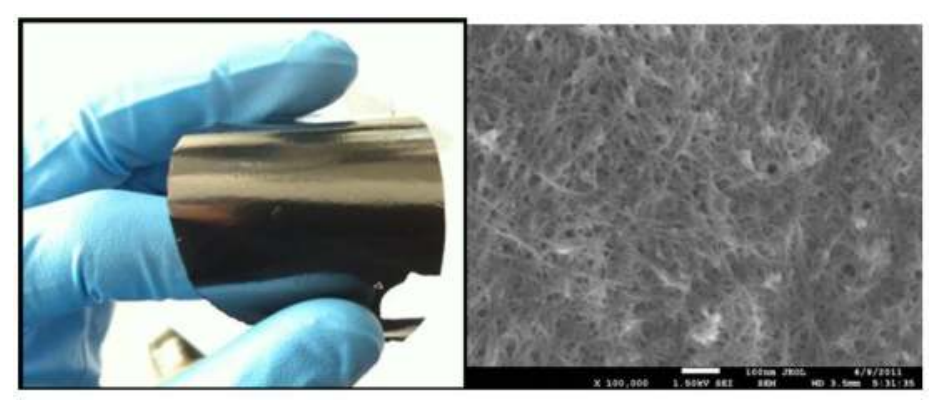

Figure 19. CNT bucky paper

Filtration of CNT dispersions results in a planar mat of randomly arranged tubes [148] that can be up to several hundred microns thick. These mats or "bucky papers" (Figure 19) have been instrumental in CNT evaluation (owing to their simple processing) as electrode materials not only for thermocells but for other electrochemical applications as well. Post-treatment of buckypapers via annealing or acid wash is essential to ensure complete removal of the solvent or surfactant used to attain the CNT dispersion [149].

\section{Chemical vapour deposition}

Chemical vapour deposition (CVD), a process that involves deposition of solids from a gas phase, has proven to be a viable method for attaining highly oriented CNTs on planar substrates (Figure 20) [150]. One of the theories behind the large degree of alignment is the reduction in free energy brought about by the van der waals interactions along the tube length 
inducing coordinated growth by holding the tubes together [151]. The ability to tailor the growth of CNTs in three dimensional configurations is highly advantageous in thermocell applications. This configuration promotes enhanced ion accessibility with the CNT matrix allowing larger current to be generated. The alignment of the tubes also minimises the tortuosity of the CNT electrodes which decreases the probability of forming concentration gradients within the electrode itself, leading to a decrease in the mass transfer overpotential. The wide range of substrates that can be used for CNT synthesis (metallic, carbon, etc) via CVD allows the fabrication of electrodes with a high degree of flexibility; materials that are highly desirable in thermocells [152].

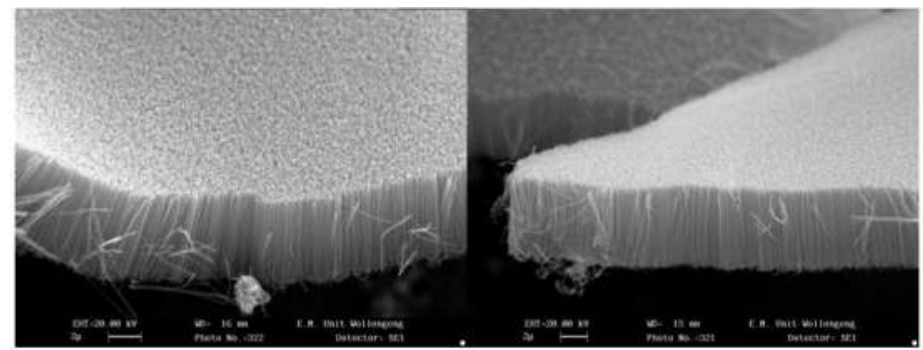

Figure 20. Aligned CNTs produced by CVD process

\subsubsection{Cell design breakthroughs attained using CNTs}

The development of flexible electrodes for electrochemical applications has paved the way for innovative cell designs for thermal energy conversion. CNT forests grown directly on thermocell casings, scroll electrodes, and thermocells that can be wrapped around cooling/ heating pipes have been attained through flexible CNT electrodes [114].

Mark II thermocell

When inter electrode separation is decreased, larger specific power is generated as mass transfer is enhanced over shorter distances. However, this results in decreased power conversion efficiency as larger thermal energy is required to maintain a similar thermal gradient [112]. Scroll electrodes (Figure 21) can be employed to mitigate this problem. Using scrolled MWNT buck papers, each with a diameter of $0.3 \mathrm{~cm}$ and mass of $0.5 \mathrm{mg}$, aligned along their rolling axis inside a glass tube containing $0.4 \mathrm{M}$ ferri/ferrocyanide, an electrode separation of $5 \mathrm{~cm}, \mathrm{~T}_{\text {cold }}$ of $5{ }^{\circ} \mathrm{C}$ and thermal gradient of $60{ }^{\circ} \mathrm{C}$ a specific power density of $1.8 \mathrm{~W} / \mathrm{m}^{2}$ was obtained. The power conversions efficiency of $0.24 \%$ is an order of magnitude higher than thermocells using Pt electrodes tested under similar conditions [114]. The relative efficiency of the Mark II thermocell is $17 \%$ higher than that obtained when using platinum electrodes, giving $\Phi_{\mathrm{r}}$ of $1.4 \%$. 


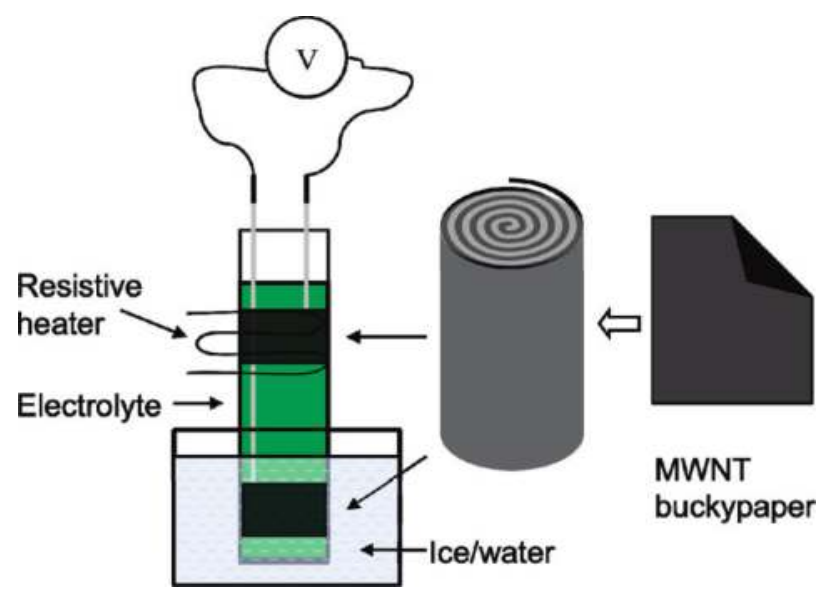

Figure 21. Mark II thermocell[114] Reprinted with permission from American Chemical Society

\section{Coin cell}

Thin coin type thermocells which could be powered by extremely low thermal gradients were developed using MWNTs and 0.4M ferri/ferrocyanide as the electrolyte (Figure 22). Coin cells fabricated using MWNT bucky paper electrodes and exposed to a thermal gradient of $45^{\circ} \mathrm{C}$ generated a specific power of $0.389 \mathrm{~W} / \mathrm{m}^{2}$ (equivalent to a normalised power density $\mathrm{P}_{\max } / \Delta \mathrm{T}^{2}$ of $1.92 \times 10^{-4} \mathrm{~W} / \mathrm{m}^{2} \mathrm{~K}$ ). Coin cells with electrodes made of MWNT forests around $100 \mu \mathrm{m}$ tall, grown directly on the internal stainless steel surface of the packaging substrate using a trilayer catalyst $(30 \mathrm{~nm} \mathrm{Ti}, 10 \mathrm{~nm} \mathrm{Al}, 2 \mathrm{~nm} \mathrm{Fe})$ plasma enhanced CVD method was also developed. The specific power generated at a thermal gradient of $60^{\circ} \mathrm{C}$ was $0.980 \mathrm{~W} / \mathrm{m}^{2}$, giving $\mathrm{P}_{\max } / \Delta \mathrm{T}^{2}=2.72 \times 10^{-4} \mathrm{~W} / \mathrm{m}^{2} \mathrm{~K}$. The larger normalised power density of the coin cell with MWNT forest electrodes is due to its nanotube alignment, which promotes electrolyte diffusion, and the lower thermal $\left(0.01 \mathrm{~cm}^{2} \mathrm{~K} / \mathrm{W}\right)$ and electrical resistance at the MWNT forest/substrate junction [153]. The thermal resistance for bucky papers is around $0.05 \mathrm{~cm}^{2} \mathrm{~K} / \mathrm{W}$ which leads to larger loss of thermal energy at the electrode/substrate junction and $30 \%$ less power conversion efficiency [154].
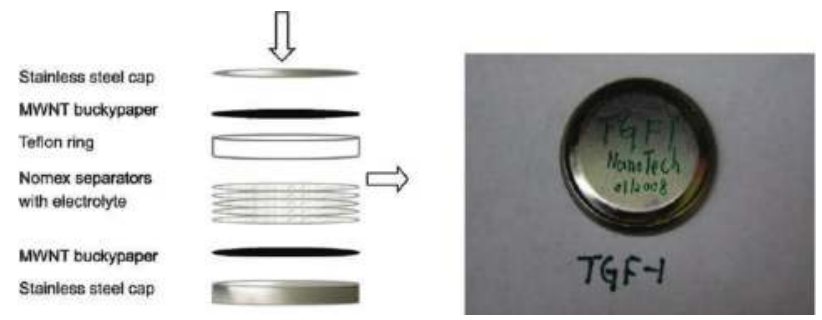

Figure 22. Coin cell for thermal energy conversion [114] Reprinted with permission from American Chemical Society 


\section{Flexible thermocell}

One of the main applications of thermocells is to harvest thermal energy from automobile exhaust pipes and cooling or heating lines in industrial facilities. Flexible thermocells can be wrapped around these pipes and convert them to sources of electrical power. A flexible thermocells consisting of two MWNTbucky paper electrodes kept apart by 2 layers of NomexHT 4848 impregnated with $0.4 \mathrm{M}$ ferri/ferrocyanide and wrapped in a stainless steel sheetis shown in Figure 23. The cell was wrapped around a cooling pipe and a thermal gradient of $15^{\circ} \mathrm{C}$ was applied using a resistive heater. A specific power $0.39 \mathrm{~W} / \mathrm{m}^{2}$ was generated proving that flexible thermocells are now a possibility [114].
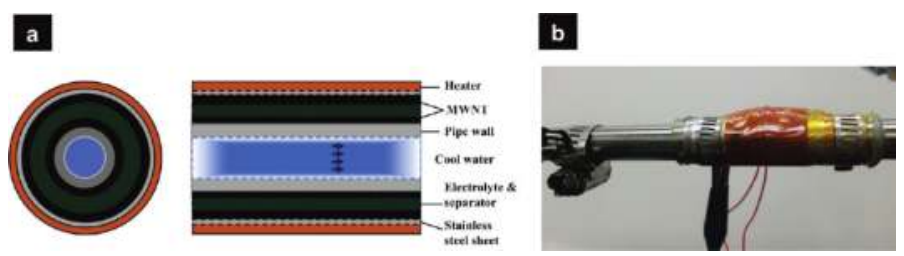

Figure 23. a) schematic b) photo of a flexible thermocell that can be wrapped around cooling/heating pipes [114] Reprinted with permission from American Chemical Society

\subsection{Conclusion}

Research on CNTs as electrode materials for thermogalvanic cells is still in its early stages. However, these initial results indicate that these nanocarbons are capable of generating significant amounts of power; much larger than when conventional electrodes are used. Without excluding the energy input from mechanical stirring, thermocells with platinum electrodes are able to attain a power conversion efficiency relative to a Carnot engine of $1.2 \%$ [100]. This value was surpassed with the use of CNT electrodes, reaching $\Phi_{\mathrm{r}}=1.4 \%$, in a thermocell that did not utilise any mechanical stirring and relied only on convection and diffusion to cause mass transfer of reaction products. The most important breakthrough is in the area of cell design as the robustness of CNT electrodes allows them to be conformed into a variety of shapes in order to mitigate heat flow from the hot to cold side of the thermocell. Flexible thermocells are also possible; devices that can harvest heat from heating or cooling pipes. Optimisation of the porosity of these CNT electrodes is essential in order to minimise the tortuosity and to reduce the mass transport overpotential in these systems. Doping CNT electrodes can alter their electroactive surface area by up to 4-fold; this feature can be exploited by selecting the right electrolyte. The use of CNT-RGO composites has demonstrated the synergistic effect of these two materials, augmenting the power conversion efficieny of thermocells. Further developments in the field of CNT synthesis and processing will decrease the cost of these materials such that commercialisation of thermogalvanic cells may one day be realised. 


\section{Perspective and future developments}

With energy consumption as a whole on the increase, coupled with the rapid economic development of countries such as Brazil, China, India, and Russia there will be a concerted effort to improve how energy is utilised. This expansion in industrialisation has already and will continue to lead to a further increase in the price of oil. Coupled to the rise in fossil fuel costs are drivers of an ageing energy infrastructure system and demand for a low-carbon emission economy through the use of renewable energy [155]. To help accommodate all these factors the supply and demand challenge may be addressed by tapping into otherwise wasted energy. Low grade heat, if effectively harvested can prove to be a viable source of power. Thermal converters have the potential to increase the efficiency of current energy conversion systems. Energy storage also plays a key role in providing a solution to the energy problem. Energy must be efficiently stored, when it is in excess, and released at a time of high demand. This is extremely important for renewables that are not load-following [156].

With these energy challenges and ongoing research and development, including those that have been conducted over the last decade, the awareness of the benefits of electrochemical capacitors is increasing. As the research and development into energy storage and conversion has increased, the applications of electrochemical capacitors has increased with the technology becoming more diverse meaning that systems can better be tailored /targeted for specific applications ranging from higher energy density to high power densities where fast charge / discharge efficiencies are needed [156]. The most commonly used material for supercapacitors has been activated carbon with new nanostructured materials such as carbon nanotubes and its derivatives coming to the forefront of the current fundamental research. It can be seen that the way forward in terms of trying to improve energy density and power density is in the use of CNT with composite materials such as other carbons, and conducting polymers or metal oxides in order to take advantage of the pseudocapacitative effects that these materials provide.

The research on thermogalvanic systems in the past has been generally limited to platinum electrodes [100]. This has enhanced the understanding of these electrochemical systems but has not advanced the research in terms of commercialisation due to its cost. The use of carbon nanomaterials has improved the performance of these devices immensely because of their fast transfer kinetics and large electroactive surface area and is also economically viable. A record threefold increase in power conversion efficiency (as compared to conventional systems wherein platinum is used) has been realised with the use of MWNT electrodes [114]. Flexible electrodes are now possible due to CNTs. These can be used as scroll electrodes or for thermocells that can be wrapped around pipes will make this system more versatile in terms of its possible applications. Further increase in thermocell performance may be realised with the use of CNTs-graphene composite materials.

Future development will most likely see supercapacitors and thermocells become a central part of hybrid energy storage and power delivery systems for large scale and domestic demand strategies. The integration of these two systems into one device will allow the converted waste heat to be stored then released when deemed necessary. These future 
advancements will not only enable better automotive and portable electronics, but they will revolutionise the fields of medicine, defence and consumer goods thus providing a step change in energy storage technology [5].

\section{Author details}

Dennis Antiohos*, Mark Romano, Jun Chen* and Joselito M. Razal

*Address all correspondence to: junc@uow.edu.au

Intelligent Polymer Research Institute, Australian Institute of Innovative Materials, Innovation Campus, University of Wollongong, Australia

\section{References}

[1] Turner, J. A. (1999). A Realizable Renewable Energy Future. Science, 285(5428), 687-689.

[2] Shukla, A. K. S. S., \& Vijayamohanan, K. (2000). Electrochemical supercapacitors: Energy storage beyond batteries. Current Science, 79.

[3] Arico, A. S., et al. (2005). Nanostructured materials for advanced energy conversion and storage devices. Nat Mater, 4(5), 366-377.

[4] Hall, P. J., et al. (2010). Energy storage in electrochemical capacitors: designing functional materials to improve performance. Energy \& Environmental Science.

[5] Hall, P. J., \& Bain, E. J. (2008). Energy-storage technologies and electricity generation. Energy Policy, 36(12), 4352-4355.

[6] Murakami, T., et al. (2003). Thermoelectric Power of M-H Systems in Molten Salts and Application to M-H Thermogalvanic Cell. Journal of The Electrochemical Society, 150(7), A928-A932.

[7] Chung, J., et al. (2004). Toward Large-Scale Integration of Carbon Nanotubes. Langmuir, 20(8), 3011-3017.

[8] Frackowiak, E, et al. (2000). Supercapacitor electrodes from multiwalled carbon nanotubes. Applied Physics Letters, 77(15), 2421.

[9] Anantram, M.P, \& Léonard, F. (2010). Physics of carbon nanotube electronic devices Rep. Prog. Phys. , 2006, 69.

[10] Pauliukaite, R., et al. Electrochemical impedance studies of chitosan-modified electrodes for application in electrochemical sensors and biosensors. Electrochimica Acta, 55(21), 6239. 
[11] Dolatshahi-Pirouz, A., et al. (2008). Bovine serum albumin adsorption on nano-rough platinum surfaces studied by QCM-D. Colloids and Surfaces B: Biointerfaces, 66(1), 53.

[12] Aaron, Davies., \& Yu, A. (2011). Material Advancements in Supercapacitors: From Activated Carbon to Carbon Nanotube and Graphene. The Canadian Journal of Chemical Engineering, 89, 1342-1357.

[13] Sherman, L. M. (2007). Carbon Nanotubes Lots of Potential--If the Price is Right. 01/05/12]; Available from:, www.ptonline.com/articles/carbon-nanotubes-lots-of-potentialif-the-price-is-right.

[14] Kierzek, K., et al. (2004). Electrochemical capacitors based on highly porous carbons prepared by $\mathrm{KOH}$ activation. Electrochimica Acta, 49(4), 515-523.

[15] Izadi-Najafabadi, A., et al. Extracting the Full Potential of Single-Walled Carbon Nanotubes as Durable Supercapacitor Electrodes Operable at $4 \mathrm{~V}$ with High Power and Energy Density. Advanced Materials.

[16] Kim, B. C., et al. (2009). Capacitive properties of $\mathrm{RuO} 2$ and Ru-Co mixed oxide deposited on single-walled carbon nanotubes for high-performance supercapacitors. Synthetic Metals, 159(13), 1389-1392.

[17] Bard, A. J., \& Faulkner, L. R. (2001). Electrochemical Methods: Fundamentals and Applications. John Wiley \& Sons, Inc.

[18] Yoon, S., et al. (2009). Preparation of mesoporous carbon/manganese oxide materials and its application to supercapacitor electrodes. Journal of Non-Crystalline Solids, 355(4-5), 252-256.

[19] Snook, G. A., Kao, P., \& Best, A. S. (2011). Conducting-polymer-based supercapacitor devices and electrodes. Journal of Power Sources, 196(1), 1-12.

[20] Qu, Q. T., Wang, B., Yang, L. C., Shi, Y., Tian, S., \& Wu, Y. P. (2008). Study on electrochemical performance of activated carbon in aqueous Li2SO4, Na2SO4 and $\mathrm{K} 2 \mathrm{SO} 4$ electrolytes. Electrochemistry Communications, 10(10), 1652-1655.

[21] Bose, S., et al. (2012). Carbon-based nanostructured materials and their composites as supercapacitor electrodes. Journal of Materials Chemistry, 22(3), 767-784.

[22] Zhou, C. (2006). Carbon Nanotube Based Electrochemical Supercapacitors, in School of Polymer, Textile and Fiber Engineering. Georgia Institute of Technology: Atlanta, Georgia.

[23] Inagaki, M., Konno, H., \& Tanaike, O. (2010). Carbon materials for electrochemical capacitors. Journal of Power Sources, 195(24), 7880-7903.

[24] Subramanian, V. R., Devan, S., \& White, R. E. (2004). An approximate solution for a pseudocapacitor. Journal of Power Sources, 135(1-2), 361-367. 
[25] Delahay, P., \& Holub, K. (1968). Coupling of charging and faradaic processes: Electrode admittance for reversible processes. Journal of Electroanalytical Chemistry, 16(2), 131-136.

[26] Liu, T. C., Pell, W. G., \& Conway, B. E. (1999). Stages in the development of thick cobalt oxide films exhibiting reversible redox behavior and pseudocapacitance. Electrochimica Acta, 44(17), 2829-2842.

[27] Pollak, E., Salitra, G., \& Aurbach, D. (2007). Can conductivity measurements serve as a tool for assessing pseudocapacitance processes occurring on carbon electrodes? Journal of Electroanalytical Chemistry, 602(2), 195-202.

[28] Bradley, D. (2010). Ordered energy storage: Energy. Materials Today, 13(1-2), 9.

[29] Presser, V., Heon, M., \& Gogotsi, Y. (2011). Carbide-Derived Carbons- From Porous Networks to Nanotubes and Graphene. Advanced Functional Materials, 21(5), 810-833.

[30] Zhang, L. L., \& Zhao, X. S. (2009). Carbon-based materials as supercapacitor electrodes. Chemical Society Reviews, 38(9), 2520-2531.

[31] Battery and Energy Technologies. (2012). Available from:, http://www.mpoweruk.com/performance.htm.

[32] Conway, B. E. (1999). Electrochemical Supercapacitors: Scientific Fundamentals and Technological Applications. New York: Kluwer Acedemic / Plenum Publishers.

[33] Jong, H. J., et al. (2006). Supercapacitor Performance of Hydrous Ruthenium Oxide Electrodes Prepared by Electrophoretic Deposition. Journal of The Electrochemical Society, 153(2), A321-A328.

[34] Lewandowski, A., et al. (2010). Performance of carbon-carbon supercapacitors based on organic, aqueous and ionic liquid electrolytes. Journal of Power Sources, 195(17), 5814-5819.

[35] Kötz, R, \& Carlen, M. (2000). Principles and applications of electrochemical capacitors. Electrochimica Acta, 45(15-16), 2483-2498.

[36] Balducci, A., et al. (2004). Ionic liquids for hybrid supercapacitors. Electrochemistry Communications, 6(6), 566-570.

[37] Frackowiak, E., Lota, G., \& Pernak, J. (2005). Room-temperature phosphonium ionic liquids for supercapacitor application. Applied Physics Letters, 86(16), 164104-164103.

[38] Wei, D., \& Ivaska, A. (2008). Applications of ionic liquids in electrochemical sensors. Analytica Chimica Acta, 607(2), 126-135.

[39] Iijima, S. (1991). Helical microtubules of graphitic carbon. Nature, 354(6348), 56-58.

[40] Yu, B, et al. (2006). The electrolyte switchable solubility of multi-walled carbon nanotube/ionic liquid (MWCNT/IL) hybrids. Chemical Communications [22], 2356-2358. 
[41] Liu, J., et al. (2008). Postsynthesis microwave treatment to give high-purity multiwalled carbon nanotubes. AIChE Journal, 54(12), 3303-3307.

[42] Che, G., et al. (1999). Metal-Nanocluster-Filled Carbon Nanotubes:â€\%o Catalytic Properties and Possible Applications in Electrochemical Energy Storage and Production. Langmuir, 15(3), 750-758.

[43] Meyyappan, M. (2005). Carbon Nanotubes: Science \& Applications. Boca Raton: CRC Press.

[44] Cai, X., Cong, H., \& Liu, C. (2012). Synthesis of vertically-aligned carbon nanotubes without a catalyst by hydrogen arc discharge. Carbon, 50(8), 2726-2730.

[45] Liu, C, et al. (1999). Semi-continuous synthesis of single-walled carbon nanotubes by a hydrogen arc discharge method. Carbon, 37(11), 1865-1868.

[46] Yuge, R., et al. (2012). Characterization and field emission properties of multi-walled carbon nanotubes with fine crystallinity prepared by CO2 laser ablation. Applied Surface Science.

[47] Zhihua, P, et al. (2008). Investigation of the microwave absorbing mechanisms of HiPco carbon nanotubes. Physica E: Low-dimensional Systems and Nanostructures, 40(7), 2400-2405.

[48] Nikolaev, P. (2004). Gas-phase production of single-walled carbon nanotubes from carbon monoxide: A review of the HiPco process. Journal of Nanoscience and Nanotechnology, 307-316.

[49] Michael, J. Bronikowski, et al. (2001). Gas-phase production of carbon single-walled nanotubes from carbon monoxide via the HiPco process: A parametric study. J. Vac. Sci. Technol. A., 19, 1800.

[50] Wang, G., Zhang, L., \& Zhang, J. (2012). A review of electrode materials for electrochemical supercapacitors. Chemical Society Reviews, 797-828.

[51] Huang, C. W., et al. (2012). Electric double layer capacitors based on a composite electrode of activated mesophase pitch and carbon nanotubes. Journal of Materials Chemistry, 7314-7322.

[52] Dai, L. (2006). Carbon Nanotechnology. Amsterdam: Elsevier.

[53] Deng, F., \& Zheng, Q. (2009). Interaction models for effective thermal and electric conductivities of carbon nanotube composites. Acta Mechanica Solida Sinica, 22(1), $1-17$.

[54] Obreja, V. V. N. (2008). On the performance of supercapacitors with electrodes based on carbon nanotubes and carbon activated material--A review. Physica E: Low-dimensional Systems and Nanostructures, 40(7), 2596-2605.

[55] Kay, Hyeok An, et al. (2001). Characterization of Supercapacitors Using Singlewalled Carbon Nanotube Electrodes. Journal of the Korean Physical Society, 39, S511-S517. 
[56] Hu, S., Rajamani, R., \& Yu, X. (2012). Flexible solid-state paper based carbon nanotube supercapacitor. Applied Physics Letters, 100(10).

[57] School of Pharmacy, . Research Program: University of Waterloo. 20/16/12]; Available from:, http://science.uwaterloo.ca/ foldvari/images/SWNT-MWNT.jpg.

[58] Morant, C., et al. (2012). Mo-Co catalyst nanoparticles: Comparative study between TiN and Si surfaces for single-walled carbon nanotube growth. Thin Solid Films, 39(520), 16-5238.

[59] Candelaria, S. L., et al. (2012). Nanostructured carbon for energy storage and conversion. Nano Energy, 1(2), 195-220.

[60] Chen, P. J. C., Qiu, J., \& Zhou, C. (2010). Nano Research, 3, 594-603.

[61] Chau, T. T., et al. (2009). A review of factors that affect contact angle and implications for flotation practice. Advances in Colloid and Interface Science, 150(2), 106-115.

[62] Kuratani, K., , T. K., \& Kuriyama, N. (2009). Journal of Power Sources, 189, 1284-1291.

[63] Bakhmatyuk, B. P., , B. Y. V., Grygorchak, I. I., \& Micov, M. M. (2008). Journal of Power Sources, 180, 890-895.

[64] Pan, H., Li, J., \& Feng, Y. (2010). Carbon Nanotubes for Supercapacitor. Nanoscale Research Letters, 5(3), 654-668.

[65] Fuertes, A. B., et al. (2005). Templated mesoporous carbons for supercapacitor application. Electrochimica Acta, 50(14), 2799-2805.

[66] Shen, J., et al. (2011). How carboxylic groups improve the performance of single-walled carbon nanotube electrochemical capacitors? Energy \& Environmental Science, $4(10), 4220-4229$.

[67] Wu, Z. S., et al. (2011). Doped Graphene Sheets as Anode Materials with Superhigh Rate and Large Capacity for Lithium Ion Batteries. ACS Nano, 5463-5471.

[68] Babel, K., \& Jurewicz, K. (2002). Electrical capacitance of fibrous carbon composites in supercapacitors. Fuel Processing Technology, 77-78, 181-189.

[69] Béguin, F, et al. (2005). A Self-Supporting Electrode for Supercapacitors Prepared by One-Step Pyrolysis of Carbon Nanotube/Polyacrylonitrile Blends. Advanced Materials, 17(19), 2380-2384.

[70] Drage, T. C., et al. (2007). Preparation of carbon dioxide adsorbents from the chemical activation of urea-formaldehyde and melamine-formaldehyde resins. Fuel, 86(1-2), 22-31.

[71] Inagaki, N., et al. (2007). Implantation of amino functionality into amorphous carbon sheet surfaces by NH3 plasma. Carbon, 45(4), 797-804. 
[72] Li, W., et al. (2007). Nitrogen enriched mesoporous carbon spheres obtained by a facile method and its application for electrochemical capacitor. Electrochemistry Communications, 9(4), 569-573.

[73] Stein, A., Wang, Z., \& Fierke, M. A. (2009). Functionalization of Porous Carbon Materials with Designed Pore Architecture. Advanced Materials, 21(3), 265-293.

[74] Peigney, A., et al. (2001). Specific surface area of carbon nanotubes and bundles of carbon nanotubes. Carbon, 39(4), 507-514.

[75] Niu, J. J., et al. (2007). An approach to carbon nanotubes with high surface area and large pore volume. Microporous and Mesoporous Materials, 100(1-3), 1-5.

[76] Zhang, Y., et al. (2010). Preparation and electrochemical properties of nitrogen-doped multi-walled carbon nanotubes. Materials Letters, 65(1), 49-52.

[77] Lee, K. Y., et al. (2010). Influence of the nitrogen content on the electrochemical capacitor characteristics of vertically aligned carbon nanotubes. Physica E: Low-dimensional Systems and Nanostructures, 42(10), 2799-2803.

[78] Antal, A. Koósa, et al. (2010). Comparison of structural changes in nitrogen and boron-doped multi-walled carbon nanotubes. Carbon, 48(11), 3033-3041.

[79] Shiraishi, S., et al. (2006). Electric double layer capacitance of multi-walled carbon nanotubes and B-doping effect. Applied Physics A: Materials Science and Processing, 82(4), 585-591.

[80] Wang, D., , W., et al. (2008). Synthesis and Electrochemical Property of Boron-Doped Mesoporous Carbon in Supercapacitor. Chemistry of Materials, 20(22), 7195-7200.

[81] Gao, Y., et al. (2012). High power supercapacitor electrodes based on flexible TiCCDC nano-felts. Journal of Power Sources, 201(0), 368-375.

[82] Zhou, J., et al. (2009). Mesoporous carbon spheres with uniformly penetrating channels and their use as a supercapacitor electrode material. Materials Characterization, 61(1), 31-38.

[83] Korenblit, Y., et al. (2010). High-Rate Electrochemical Capacitors Based on Ordered Mesoporous Silicon Carbide-Derived Carbon. ACS Nano, 4(3), 1337-1344.

[84] Fu, C., et al. (2011). Supercapacitor based on electropolymerized polythiophene and multi-walled carbon nanotubes composites. Materials Chemistry and Physics, 132(2), 596-600.

[85] Wu, Z. S., et al. (2012). Graphene/metal oxide composite electrode materials for energy storage. Nano Energy, 1(1), 107-131.

[86] Bhandari, S., et al. (2009). PEDOT-MWNTs commposite films. J. Phys. Chem B, 113, 9416-9428.

[87] Zhang, X, et al. (2011). Ultralight conducting polymer/carbon nanotube composite aerogels. Carbon, 49(6), 1884-1893. 
[88] Crispin, X., et al. (2006). The Origin of the High Conductivity of Poly(3,4-ethylenedioxythiophene) Poly(styrenesulfonate) (PEDOT/PSS) Plastic Electrodes. Chemistry of Materials, 18(18), 4354-4360.

[89] Antiohos, D., et al. (2011). Compositional effects of PEDOT-PSS/single walled carbon nanotube films on supercapacitor device performance. Journal of Materials Chemistry, 21(40), 15987-15994.

[90] Kim, K. S., \& Park, J. S. (2011). Influence of multi-walled carbon nanotubes on the electrochemical performance of graphene nanocomposites for supercapacitor electrodes. Electrochimica Acta, 56(3), 1629-1635.

[91] Hu, Y., et al. (2012). Defective super-long carbon nanotubes and polypyrrole composite for high-performance supercapacitor electrodes. Electrochimica Acta, 60(0), 279-286.

[92] Myoungki, M., et al. (2006). Hydrous RuO2/Carbon Black Nanocomposites with 3D Porous Structure by Novel Incipient Wetness Method for Supercapacitors. Journal of The Electrochemical Society, 153(2), A334-A338.

[93] Zhai, Y., et al. (2011). Carbon materials for chemical capacitive energy storage. Advanced Materials, 23(42), 4828-4850.

[94] Shan, Y., \& Gao, L. (2007). Formation and characterization of multi-walled carbon nanotubes/Co3O4 nanocomposites for supercapacitors. Materials Chemistry and Physics (2â€“"3): , 103, 206-210.

[95] Jayalakshmi, M., et al. (2007). Hydrothermal synthesis of SnO2-V2O5mixed oxide and electrochemical screening of carbon nano-tubes (CNT), V2O5, V2O5-CNT, and $\mathrm{SnO} 2-\mathrm{V} 2 \mathrm{O} 5-\mathrm{CNT}$ electrodes for supercapacitor applications. Journal of Power Sources, 166(2), 578-583.

[96] Li, Q., et al. (2011). Structural evolution of multi-walled carbon nanotube/MnO2 composites as supercapacitor electrodes. Electrochimica Acta, 59(0), 548-557.

[97] Li, J. J., et al. (2012). Graphene/carbon nanotube films prepared by solution casting for electrochemical energy storage. IEEE Transactions on Nanotechnology, 11(1), 3-7.

[98] Dong, X., et al. (2011). The formation of a carbon nanotube-graphene oxide core-shell structure and its possible applications. Carbon, 49(15), 5071-5078.

[99] Wartanowicz, T. (1964). The theoretical analysis of a molten salt thermocell as a thermoelectric generator. Advanced Energy Conversion, 4(3), 149-158.

[100] Quickenden, T. I., \& Mua, Y. (1995). A Review of Power Generation in Aqueous Thermogalvanic Cells. Journal of The Electrochemical Society, 142(11), 3985-3994.

[101] Kuzminskii, Y. V., Zasukha, V. A., \& Kuzminskaya, G. Y. (1994). Thermoelectric effects in electrochemical systems. Nonconventional thermogalvanic cells. Journal of Power Sources, 52(2), 231-242. 
[102] Wartsila. (2012). The world's most powerful reciprocating engine. Available from:, http://www.wartsila.com/en/engines/low-speed-engines/RT-flex96C.

[103] Dincer, I. (2002). On thermal energy storage systems and applications in buildings. Energy and Buildings, 34(4), 377-388.

[104] Bell, L. E. (2008). Cooling, Heating, Generating Power, and Recovering Waste Heat with Thermoelectric Systems. Science, 321(5895), 1457-1461.

[105] Ujihara, M., Carman, G. P., \& Lee, D. G. (2007). Thermal energy harvesting device using ferromagnetic materials. Applied Physics Letters, 91(9), 093508-093503.

[106] Vining, C. B. (2009). An inconvenient truth about thermoelectrics. Nat Mater, 8(2), 83-85.

[107] Hertz, H. G., \& Ratkje, S. K. (1989). Theory of Thermocells. Journal of The Electrochemical Society, 136(6), 1698-1704.

[108] Romano, M., et al. (2012). Novel carbon materials for thermal energy harvesting. Journal of Thermal Analysis and Calorimetry, 1-7.

[109] Goncalves, R., \& Ikeshoji, T. (1992). Comparative studies of a thermoelectric converter by a thermogalvanic cell with a mixture of concentrated potassium ferrocyanide and potassium ferricyanide aqueous solutions at great temperature differences. $J$. Braz. Chem. Soc, 3(3), 4.

[110] Quickenden, T. I., \& Vernon, C. F. (1986). Thermogalvanic conversion of heat to electricity. Solar Energy, 36(1), 63-72.

[111] Artjom, V. S. (1994). Theoretical study of thermogalvanic cells in steady state. Electrochimica Acta, 39(4), 597-609.

[112] Mua, Y., \& Quickenden, T. I. (1996). Power Conversion Efficiency, Electrode Separation, and Overpotential in the Ferricyanide/Ferrocyanide Thermogalvanic Cell. Journal of The Electrochemical Society, 143(8), 2558-2564.

[113] Kang, T. J., et al. (2011). Electrical Power From Nanotube and Graphene Electrochemical Thermal Energy Harvesters.

[114] Hu, R., et al. (2010). Harvesting Waste Thermal Energy Using a Carbon-NanotubeBased Thermo-Electrochemical Cell. Nano Letters, 10(3), 838-846.

[115] Salazar, P. F., Kumar, S., \& Cola, B. A. (2012). Nitrogen- and Boron-Doped Carbon Nanotube Electrodes in a Thermo-Electrochemical Cell. Journal of The Electrochemical Society, 159(5), B483-B488.

[116] Quickenden, T. I., \& Mua, Y. (1995). The Power Conversion Efficiencies of a Thermogalvanic Cell Operated in Three Different Orientations. Journal of The Electrochemical Society, 142(11), 3652-3659. 
[117] Antiohos, D., et al. (2010). Electrochemical investigation of carbon nanotube nanoweb architecture in biological media. Electrochemistry Communications, 12(11), 1471-1474.

[118] Landi, B. J., et al. (2009). Carbon nanotubes for lithium ion batteries. Energy \& Environmental Science, 2(6), 638-654.

[119] Wang, C., et al. (2003). Proton Exchange Membrane Fuel Cells with Carbon Nanotube Based Electrodes. Nano Letters, 4(2), 345-348.

[120] Baughman, R. H., Zakhidov, A. A., \& de Heer, W. A. (2002). Carbon Nanotubes--the Route Toward Applications. Science, 297(5582), 787-792.

[121] Nugent, J. M., et al. (2001). Fast Electron Transfer Kinetics on Multiwalled Carbon Nanotube Microbundle Electrodes. Nano Letters, 1(2), 87-91.

[122] Inoue, S., et al. (1998). Capillary Condensation of N2 on Multiwall Carbon Nanotubes. The Journal of Physical Chemistry B, 102(24), 4689-4692.

[123] Eswaramoorthy, M., Sen, R., \& Rao, C. N. R. (1999). A study of micropores in singlewalled carbon nanotubes by the adsorption of gases and vapors. Chemical Physics Letters, 304(3-4), 207-210.

[124] Banks, C.E, et al. (2004). Investigation of modified basal plane pyrolytic graphite electrodes: definitive evidence for the electrocatalytic properties of the ends of carbon nanotubes. Chemical Communications [16], 1804-1805.

[125] Chun, K. Y., Lee, H. S., \& Lee, C. J. (2009). Nitrogen doping effects on the structure behavior and the field emission performance of double-walled carbon nanotubes. Carbon, 47(1), 169-177.

[126] Charlier, J. C., et al. (2002). Enhanced Electron Field Emission in B-doped Carbon Nanotubes. Nano Letters, 2(11), 1191-1195.

[127] Deng, C., et al. (2009). Electrochemical detection of 1-cysteine using a boron-doped carbon nanotube-modified electrode. Electrochimica Acta, 54(12), 3298-3302.

[128] Panchakarla, L. S., Govindaraj, A., \& Rao, C. N. R. (2007). Nitrogen- and Boron-Doped Double-Walled Carbon Nanotubes. ACS Nano, 1(5), 494-500.

[129] Gong, K., et al. (2009). Nitrogen-Doped Carbon Nanotube Arrays with High Electrocatalytic Activity for Oxygen Reduction. Science, 323(5915), 760-764.

[130] Terrones, M, et al. (2002). N-doping and coalescence of carbon nanotubes: synthesis and electronic properties. Applied Physics A: Materials Science \& Processing , 74(3), 355-361.

[131] Lee, Y. T., et al. (2003). Growth of Vertically Aligned Nitrogen-Doped Carbon Nanotubes: Control of the Nitrogen Content over the Temperature Range 900-1100 ${ }^{\circ} \mathrm{C}$. The Journal of Physical Chemistry B, 107(47), 12958-12963. 
[132] Banks, C. E., \& Compton, R. G. (2005). Exploring the electrocatalytic sites of carbon nanotubes for $\mathrm{NADH}$ detection: an edge plane pyrolytic graphite electrode study. Analyst, 130(9), 1232-1239.

[133] Deng, C., et al. (2008). Boron-doped carbon nanotubes modified electrode for electroanalysis of NADH. Electrochemistry Communications, 10(6), 907-909.

[134] Strmcnik, D., et al. (2009). The role of non-covalent interactions in electrocatalytic fuel-cell reactions on platinum. Nat Chem, 1(6), 466-472.

[135] Novoselov, K. S., et al. (2004). Electric Field Effect in Atomically Thin Carbon Films. Science, 306(5696), 666-669.

[136] Bolotin, K. I., et al. (2008). Ultrahigh electron mobility in suspended graphene. Solid State Communications, 146(9-10), 351-355.

[137] Stoller, M. D., et al. (2008). Graphene-Based Ultracapacitors. Nano Letters, 8(10), 3498-3502.

[138] Coleman, J. N. (2009). Liquid-Phase Exfoliation of Nanotubes and Graphene. Advanced Functional Materials, 19(23), 3680-3695.

[139] Park, S., et al. (2009). Colloidal Suspensions of Highly Reduced Graphene Oxide in a Wide Variety of Organic Solvents. Nano Letters, 9(4), 1593-1597.

[140] Qiu, L., et al. (2010). Dispersing Carbon Nanotubes with Graphene Oxide in Water and Synergistic Effects between Graphene Derivatives. Chemistry- A European Journal, 16(35), 10653-10658.

[141] Romano, M. S., et al. (2012). Novel Carbon Nanomaterials for Thermal Energy Converters. in International Society of Electrochemistry 10th Spring Meeting. Perth, Australia.

[142] Bergin, S.D, et al. (2009). Multicomponent Solubility Parameters for Single-Walled Carbon Nanotube-Solvent Mixtures. ACS Nano, 3(8), 2340-2350.

[143] Bergin, S.D, et al. (2008). Towards Solutions of Single-Walled Carbon Nanotubes in Common Solvents. Advanced Materials, 20(10), 1876-1881.

[144] Israelachvili, J. (1991). Intermolecular and Surface Forces. Academic Press, London.

[145] White, B., et al. (2007). Zeta-Potential Measurements of Surfactant-Wrapped Individual Single-Walled Carbon Nanotubes. The Journal of Physical Chemistry C, 111(37), 13684-13690.

[146] Hunter, R. (1994). Introduction to Modern Colloid Science. Oxford: Oxford Science Publications.

[147] Sun, Z., et al. (2008). Quantitative Evaluation of Surfactant-stabilized Single-walled Carbon Nanotubes: Dispersion Quality and Its Correlation with Zeta Potential. The Journal of Physical Chemistry C, 112(29), 10692-10699. 
[148] Liu, J., et al. (1998). Fullerene Pipes. Science, 280(5367), 1253-1256.

[149] Geng, H. Z., et al. (2008). Absorption spectroscopy of surfactant-dispersed carbon nanotube film: Modulation of electronic structures. Chemical Physics Letters, 455(4-6), 275-278.

[150] Chen, J., et al. (2007). Flexible, Aligned Carbon Nanotube/Conducting Polymer Electrodes for a Lithium-Ion Battery. Chemistry of Materials, 19(15), 3595-3597.

[151] Wei, B. Q., et al. (2003). Assembly of Highly Organized Carbon Nanotube Architectures by Chemical Vapor Deposition. Chemistry of Materials, 15(8), 1598-1606.

[152] Chen, J., et al. (2008). Direct Growth of Flexible Carbon Nanotube Electrodes. Advanced Materials, 20(3), 566-570.

[153] Myounggu, P., et al. (2006). Effects of a carbon nanotube layer on electrical contact resistance between copper substrates. Nanotechnology, 17(9), 2294.

[154] Cola, B. A., et al. (2007). Photoacoustic characterization of carbon nanotube array thermal interfaces. Journal of Applied Physics, 101(5), 054313-054319.

[155] Wilson, I. A. G., Mc Gregor, P. G., \& Hall, P. J. (2010). Energy storage in the UK electrical network: Estimation of the scale and review of technology options. Energy Policy, 38(8), 4099-4106.

[156] Hall, P. J. (2008). Energy storage: The route to liberation from the fossil fuel economy? Energy Policy, 36(12), 4363-4367. 
